\title{
Field guide to Adaptive Collaborative Management and improving women's participation
}
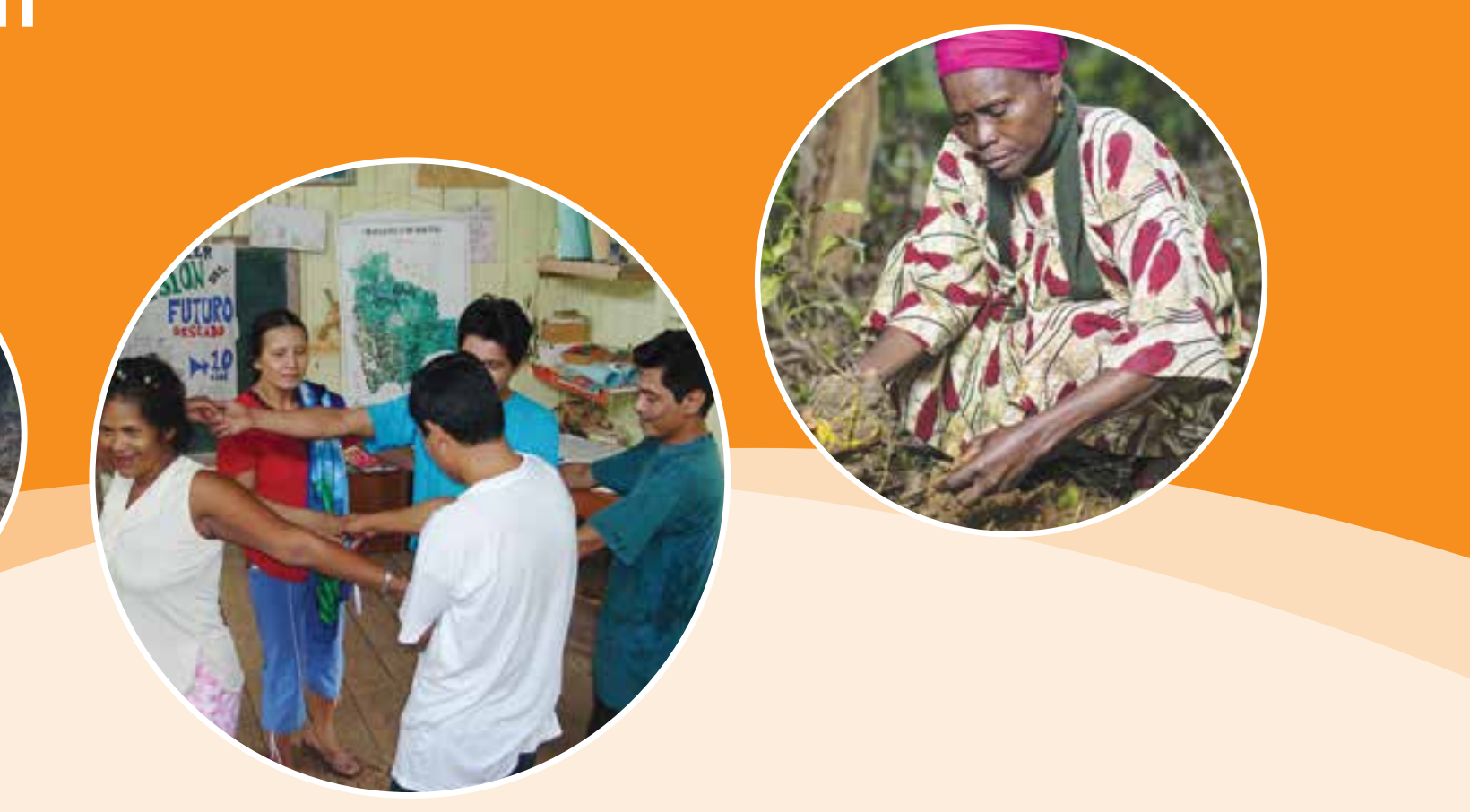

Kristen Evans, Anne Larson, Esther Mwangi, Peter Cronkleton,

Tendayi Maravanyika, Xochilt Hernandez, Pilar Müller, Alejandro Pikitle, Roberto Marchena, Concepta Mukasa, Alice Tibazalika and Abwoli Banana

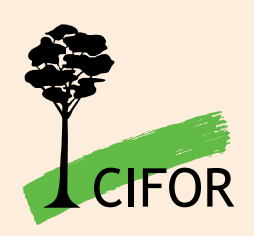





\section{Field guide to Adaptive Collaborative Management and improving women's participation}

Kristen Evans

Anne Larson

Esther Mwangi

Peter Cronkleton

Tendayi Maravanyika

Xochilt Hernandez

Pilar Müller

Alejandro Pikitle

Roberto Marchena

Concepta Mukasa

Alice Tibazalika

Abwoli Banana 
(C) 2014 Center for International Forestry Research

(c) (1) Content in this publication is licensed under a Creative Commons Attribution 4.0 International (CC BY 4.0), http://creativecommons.org/licenses/by/4.0/

Evans K, Larson A.M., Mwangi E, Cronkleton P, Maravanyika T, Hernandez X, Müller P, Pikitle A, Marchena R, Mukasa C, Tibazalika A and Banana A. 2014. Field guide to Adaptive Collaborative Management and improving women's participation. Bogor, Indonesia: CIFOR.

Cover photos by Kristen Evans, Michael Padmanaba and Ollivier Girard

Inside photos: Unless otherwise indicated, photos by Kristen Evans

ISBN 978-602-1504-40-6

CIFOR

Jl. CIFOR, Situ Gede

Bogor Barat 16115

Indonesia

$\mathrm{T}+62(251) 8622-622$

$\mathrm{F}+62$ (251) 8622-100

E cifor@cgiar.org

cifor.org

We would like to thank all donors who supported this research through their contributions to the CGIAR Fund. For a list of Fund donors please see: https://www.cgiarfund.org/FundDonors

Any views expressed in this book are those of the authors. They do not necessarily represent the views of CIFOR, the editors, the authors' institutions, the financial sponsors or the reviewers. 


\section{Table of contents}

\section{Acknowledgments}

\section{Foreword}

1. Introduction

1.1 Purpose of this manual

1.2 Why ACM?

1.3 Who the manual is for

1.4 How to use the manual

2. Understanding ACM

2.1 Basic definition of ACM

2.2 ACM and women's participation

2.3 More ACM applications

2.4 Where ACM came from

3. Putting ACM into practice

3.2 Identify priorities

3.3 Make a plan

3.4 Monitor and reflect $\quad 27$

3.5 Take action 35

3.6 Reflect and take new action 37

$\begin{array}{ll}3.7 & \text { Improving women's participation } \\ \end{array}$

4. Additional resources 41

4.1 Facilitation skills $\quad 41$

4.2 More facilitation tips 43

4.3 Gender monitoring worksheet $\quad 43$

5. References 45

5.1 Publications $\quad 45$

5.2 Websites 46 


\section{Figures, boxes and tables}

\section{Figures}

1 The ACM "worm" shows how systematic learning helps us adapt to change 7

2 ACM activities

3 Example of a pathways plan developed in Amazonian Bolivia to finish an incomplete water well project in the community

4 What is monitoring?

5 Community member shares her results of monitoring participation of women and men

\section{Boxes}

1 CIFOR's definition of ACM

2 ACM and gender in Nicaragua and Uganda

3 Spreading the ACM knowledge

4 Money and incentives

5 Always new participants

6 Taking ACM to the women

7 How do you say "monitoring" in..

8 Monitoring the books in Bolivia, and learning along the way

9 ACM can start with a simple question

10 Monitoring gender yields surprising results

11 Priming the pump

12 Challenges of managing a new project

13 Gender issues in Nicaragua

\section{Tables}

1 Examples of indicators 31

2 Creating a basic monitoring plan 32 


\section{Acknowledgments}

We are grateful to the many people from around the world who contributed to this manual by sharing their experiences, knowledge or resources. First of all, we thank the communities that collaborated with us in the action research project Gender, Tenure and Community Forests in Uganda and Nicaragua: AwasTingni, Fruta de Pan, Iltara, Kisalaya, Layasiksa, Mukuswas, Sahsa, Sante Fe, and Saupuka in Nicaragua; and the communities of Mbazzi, Nkinga, Bukeeri, Kagologolo, Kajoki and Kizira in Uganda. Our local institutional partners were key collaborators in every stage of the project, including our Nicaraguan partners Nitlapan of the Universidad Centroamericana (UCA) and our Ugandan partners, Makerere Universityand the Association of UgandaProfessional Women in Agriculture and Environment (AUPWAE). Our local Advisory Committee members in both Nicaragua and Uganda provided invaluable guidance and feedback throughout the project.
We would like to thank the community members, local leaders and local and global partners who have collaborated with CIFOR in the development of ACM methodologies over the past two decades. Likewise, we are indebted to the work of the many scientists and field practitioners who have contributed to development of ACM and related methodologies over the years. We also thank the many community members and researchers featured in the photos. This manual builds directly on their work. We are deeply grateful to the Austrian Development Agency (ADA) and to the CGIAR Research Program on Forest, Trees and Agriculture, which provided the funding for the research project and the development of this manual. We especially thank the reviewers who contributed their invaluable comments to this manual, including Carol Colfer, Yayan Indriatmoko, and Anne Marie Tiani.

Finally, special thanks go to the CIFOR Information Communications Group team for their expertise and advice in the design, layout, editing and printing of this manual. 


\section{Foreword}

Women are crucial actors in forest management, yet their involvement in decision making has not kept pace with reforms in broader political and economic systems. In the past 30 years, global approaches to forest management have tended towards greater inclusion and participation, shifting from state-centric management through co-management to devolving authority to communities. Yet increasing evidence suggests that women-who are amongst the poorest of the poor, and who depend on forest resources for subsistence, as safety nets and for income-continue to be marginalised in rule making processes and in the distribution of forest resource benefits. The need to understand and to remedy this continued lack of involvement is urgent. Increasing global interconnectedness, international trade and climate change are anticipated to further increase the vulnerability of women's rights to resources in rural settings.

The idea for this manual arose from a research project of the Center for International Forestry Research (CIFOR), funded by the Austrian Development Agency (ADA), on Gender, Tenure and Community Forests in Uganda and Nicaragua. The overall goal of the project was to improve women's tenure rights to forests through their increased participation in community forest user groups with regard both to decision making and livelihood benefits. We also aimed to enhance stakeholder uptake of institutional and policy innovations to promote women's participation, specifically regarding how community forest decisions include women and reflect their interests.

We chose to use Adaptive Collaborative Management (ACM), an innovative methodology that was developed by CIFOR scientists and their partners in the 1990s. ACM uses participatory action research to initiate, support and encourage joint and iterative learning within and amongst local communities and relevant government and nongovernmental actors. The methodology is experimental and transformative. It draws on local processes, decisions and learning to improve natural resource management. We used ACM to help overcome the key barriers to women's participation identified by men and women and by our research. ACM permitted researchers to facilitate the implementation of specific forest-related interventions developed by community members, while using those interventions to strengthen women's rights and access to forests, and to deepen their participation in decision making by building their confidence and skills.

We used ACM to identify women's and men's forestry-related challenges, constraints and priorities; develop and implement action plans for addressing these challenges; and generate indicators for monitoring and evaluating achievements against the action plans. Communities monitor implementation and evaluate their achievements. ACM has often been used to improve forest management, and sometimes to work with women specifically. We hope that this manual will help facilitators address the specific challenges of using ACM in mixed groups to improve forest management while at the same time promoting women's participation with a broader goal of transforming gender relations towards greater equity.

Like ACM, the production of this manual was a collaborative process. Our partners in Uganda (from Makarere University and the Association of Uganda Professional Women in Agriculture and Environment) and Nicaragua (from Nitlapan Institute for Research and Development, Central American University) shared, discussed and debated their experiences addressing gender issues through ACM under the guidance of Kristen Evans, who, together with Tendayi Maravanyika, was responsible for training the teams from the beginning of the project. Both groups provided invaluable feedback throughout its production. We hope that you will find it useful.

Anne Larson and Esther Mwangi 


\section{Introduction}

\subsection{Purpose of this manual}

The purpose of this manual is to provide practical guidance and examples of how to apply Adaptive Collaborative Management (ACM) methods in communities and how to teach those methods to others. ACM is a collective problem-solving and management approach. With ACM everybody can participate, contribute their knowledge and learn together how to solve important problems. ACM focuses on learning - from our mistakes and our successes. Specifically, ACM uses social learning, a process through which individuals work with others to observe, evaluate and decide upon actions together so that decisions about natural resource management can be more adaptive and collaborative. Community members around the world have used ACM approaches in a range of ways to help them manage their natural resources better, more fairly and more inclusively. Most importantly, ACM has helped people learn together to plan and prepare for the future.

This manual specifically addresses how to encourage the broader participation of women in decision making through ACM. Women are often marginalized when it comes to decision making over forest resource management. During a project on gender and tenure in Nicaragua and Uganda, ${ }^{1}$ we used ACM to create new spaces for women to participate and to build understanding between women and men about the benefits of getting women involved in forest management.

1 This manual was created as part of the project Gender, Tenure and Community Forests in Uganda and Nicaragua.

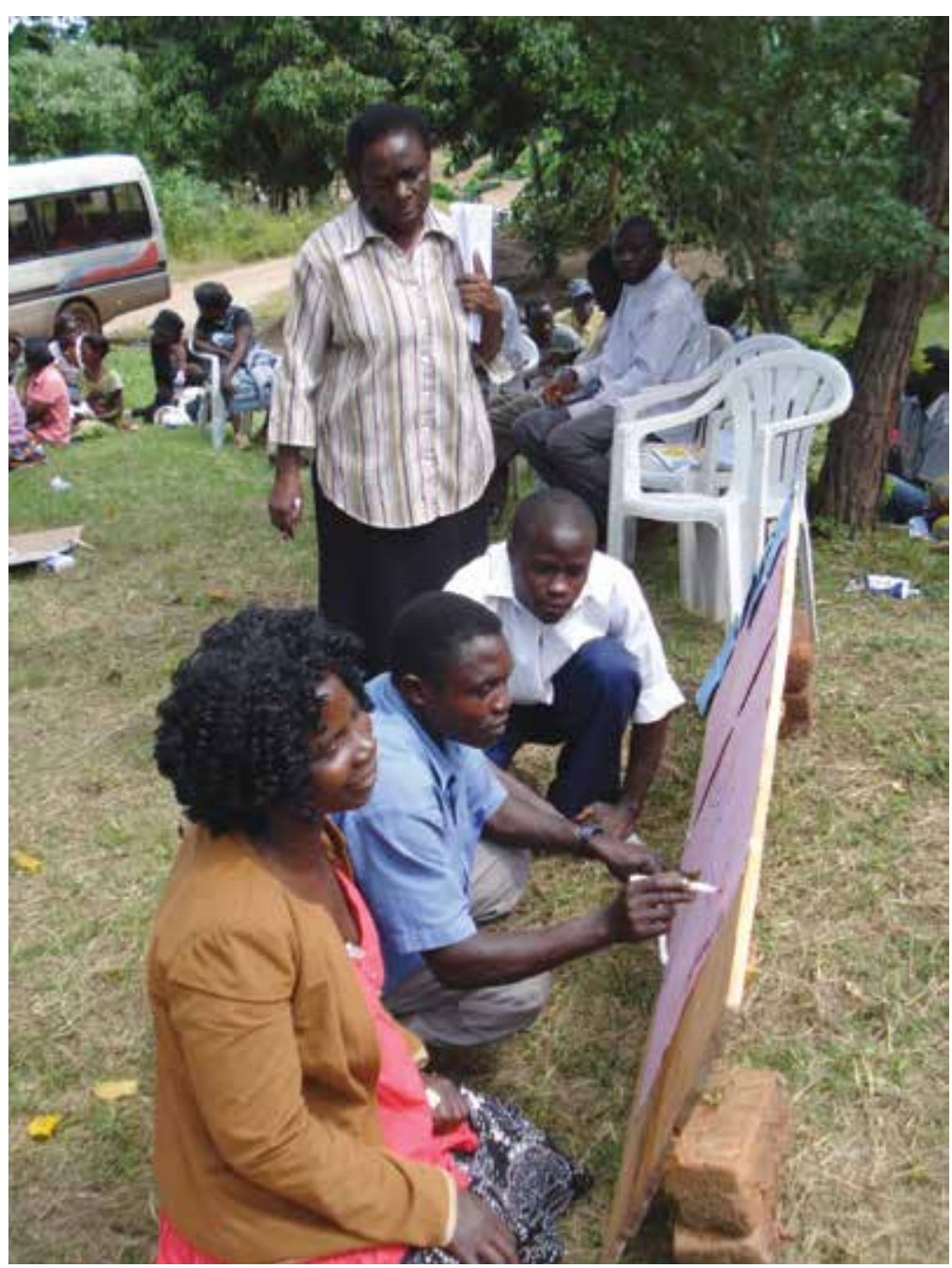

\subsection{Why ACM?}

- In ACM, community members control the process as active participants so that decisions come from within the community and better reflect community interests. 


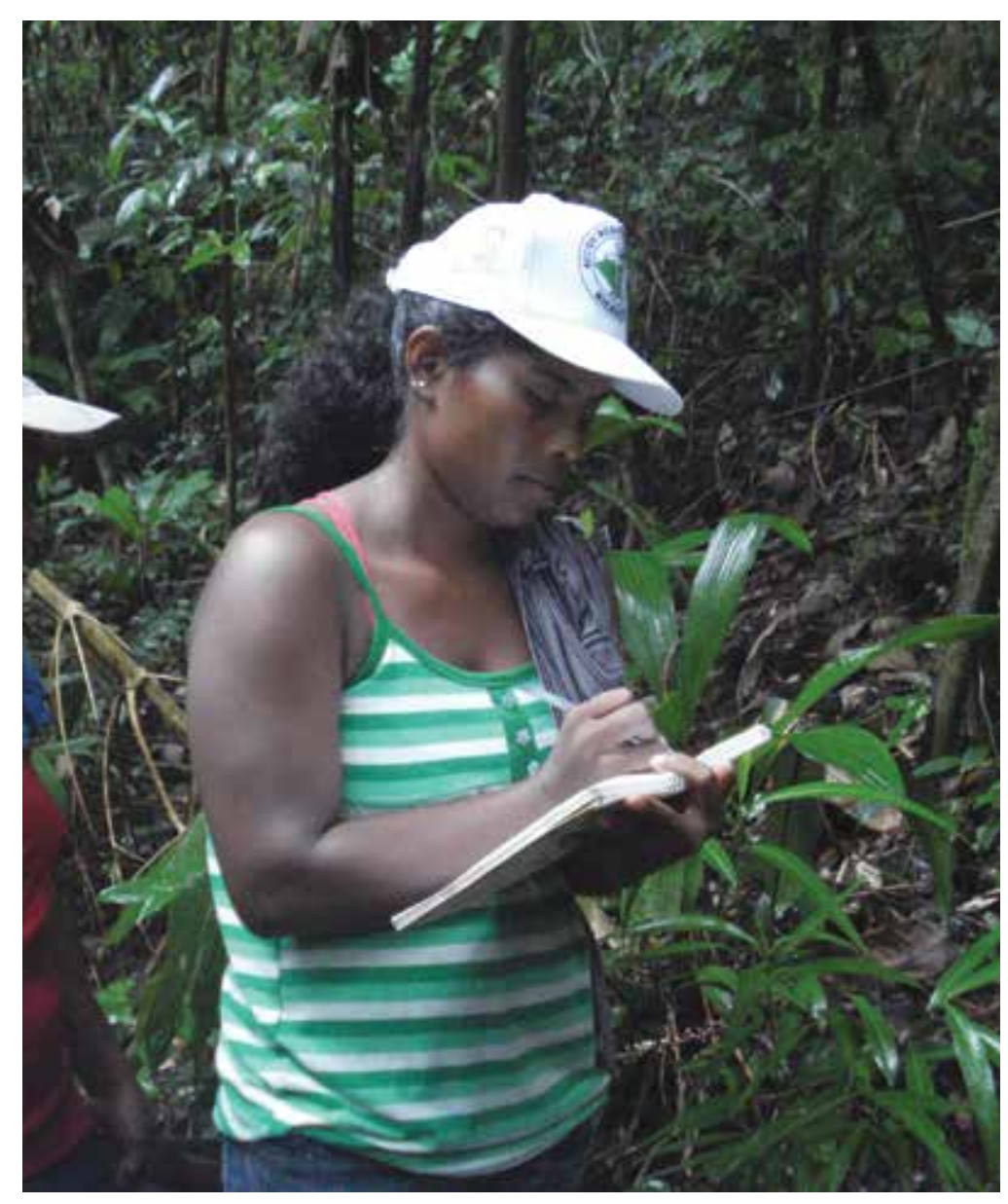

- Once a community learns how to do ACM, community members can do it whenever there is a need and on their own.

- ACM can lead to important governance changes that have outcomes far beyond the specific task at hand, such as stronger self-confidence, systematic equitable decision making, a platform that facilitates the participation of marginalized groups or a mechanism for accommodating multiple interests and views.
- ACM can improve the participation of women and marginalized groups in decision making by opening up new spaces for them to express their opinions, share their knowledge and learn.

- ACM can be relatively inexpensive compared with many externally funded projects. This is because ACM focuses on decision making and activities that the community can do without introducing large sums of money. However, ACM does require ongoing involvement by some trained personnel over fairly long time periods.

\subsection{Who the manual is for}

This manual is for facilitators working with community members managing — or who want to manage better — their resources.

If you are a facilitator, perhaps you have just been instructed to start using ACM in your community or your project and you are wondering where to start. Or perhaps you have heard about ACM, but are not sure what it really is or how to do it. Maybe you are simply interested in learning about ACM. This manual is for you.

We recognize that not everyone has the opportunity to attend an ACM workshop, or invite an ACM trainer to show them the ropes. ACM theory might not answer your questions about how to actually implement it in practice. This handbook will provide you with the basics of what you need to know to start applying ACM-based approaches in your work on your own. The handbook can serve as a manual for an ACM training course for facilitators in ACM methods, and it can also serve as a reference for practitioners who are already doing ACM. 


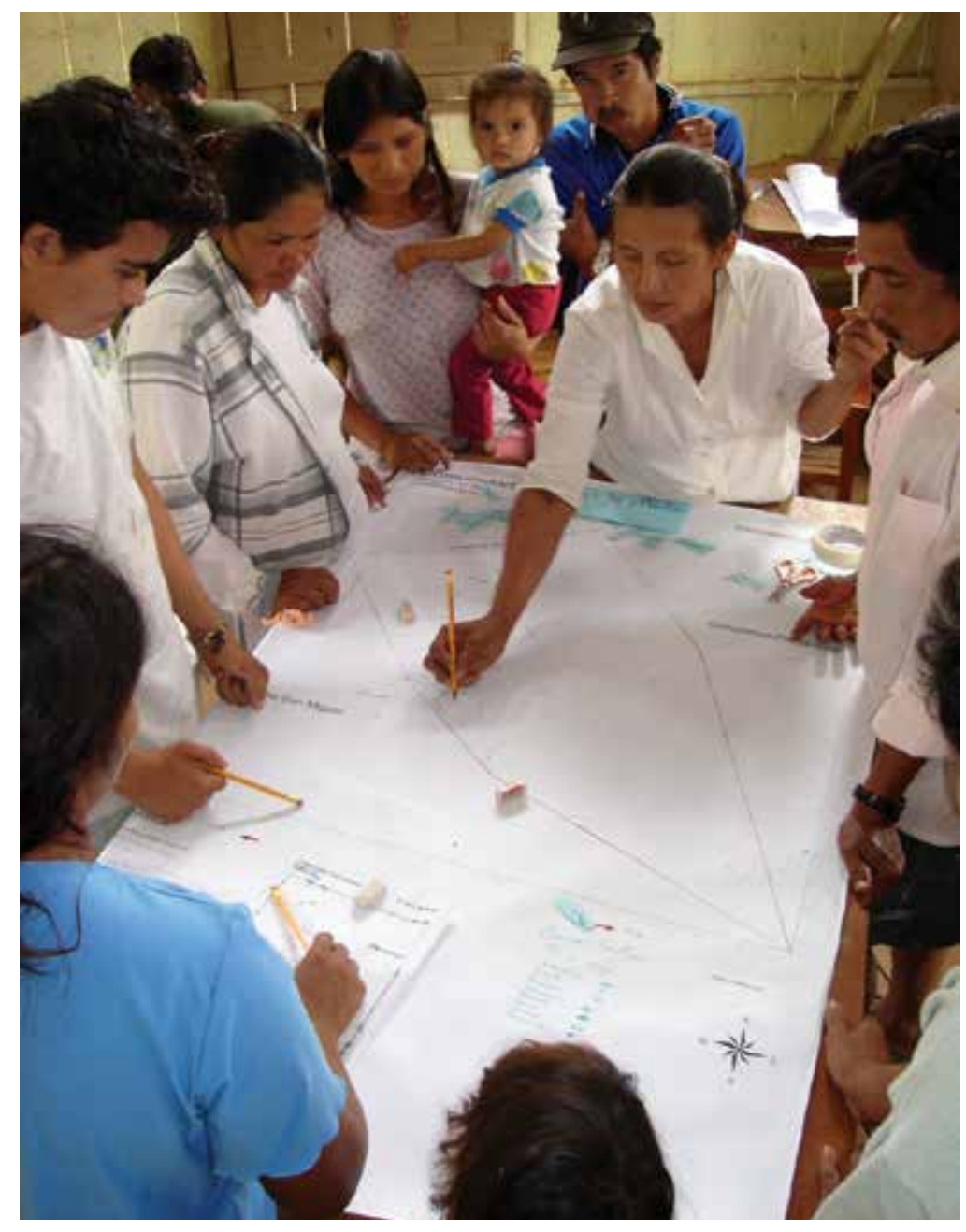

The ideas and activities that we present here come from field practitioners and community members who are managing forests, or who want to manage them better. It specifically addresses how ACM can help improve the participation of women in decision making. However, this manual can also be applied to the management of a wide range of natural resources, such as natural forests, planted forests, crops, gardens, water or animals.

\subsection{How to use the manual}

If you are completely new to ACM, spend some time on the "Understanding ACM" section for a review of the ideas and history behind ACM. If you are ready to start work in your community, you may want to skip to the "Putting ACM into practice" section, where you will find suggested steps and activities for getting the ball rolling. Tips and case studies are sprinkled throughout so that you can learn from others. This manual is not meant to be your only source of information on ACM, so be sure to check out the "Additional resources" section too.

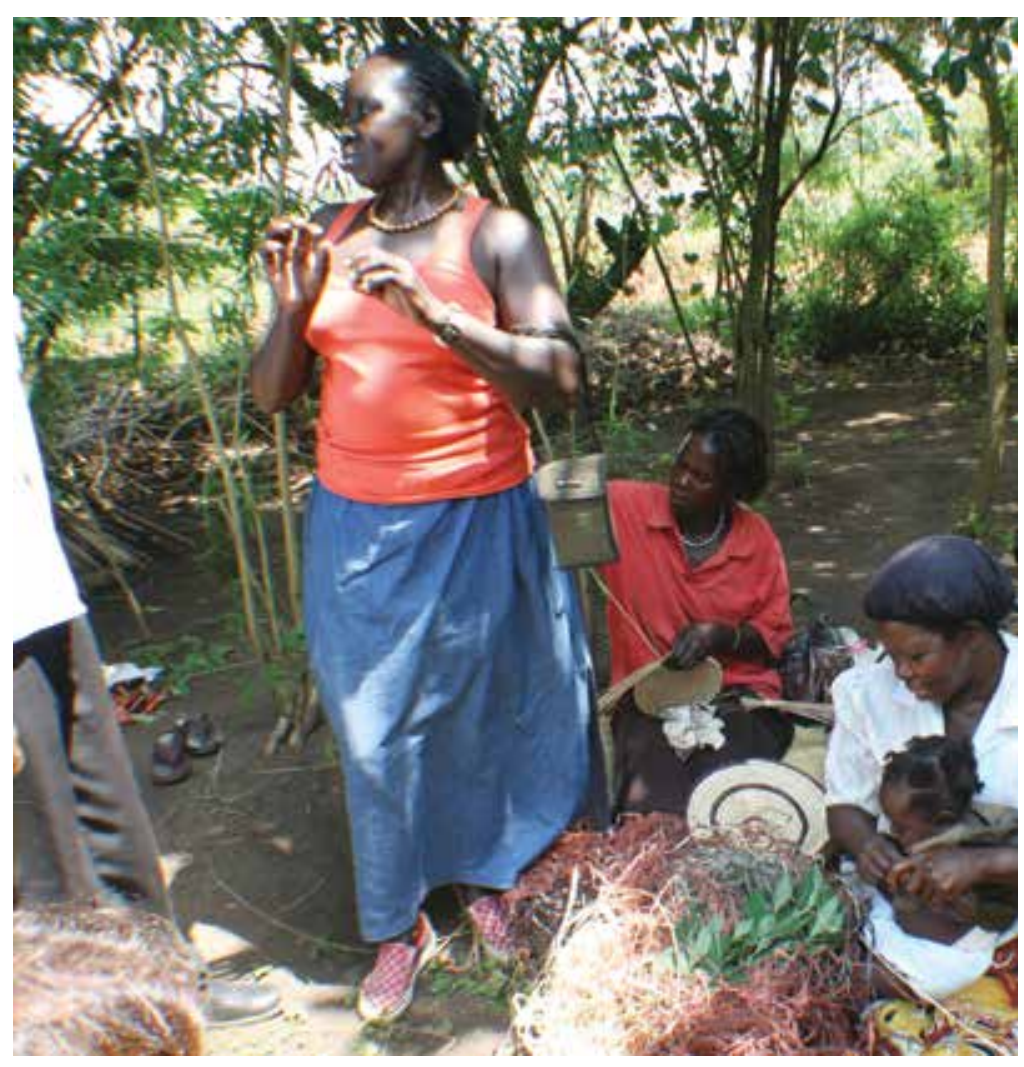

Photo by Terry Sunderland 


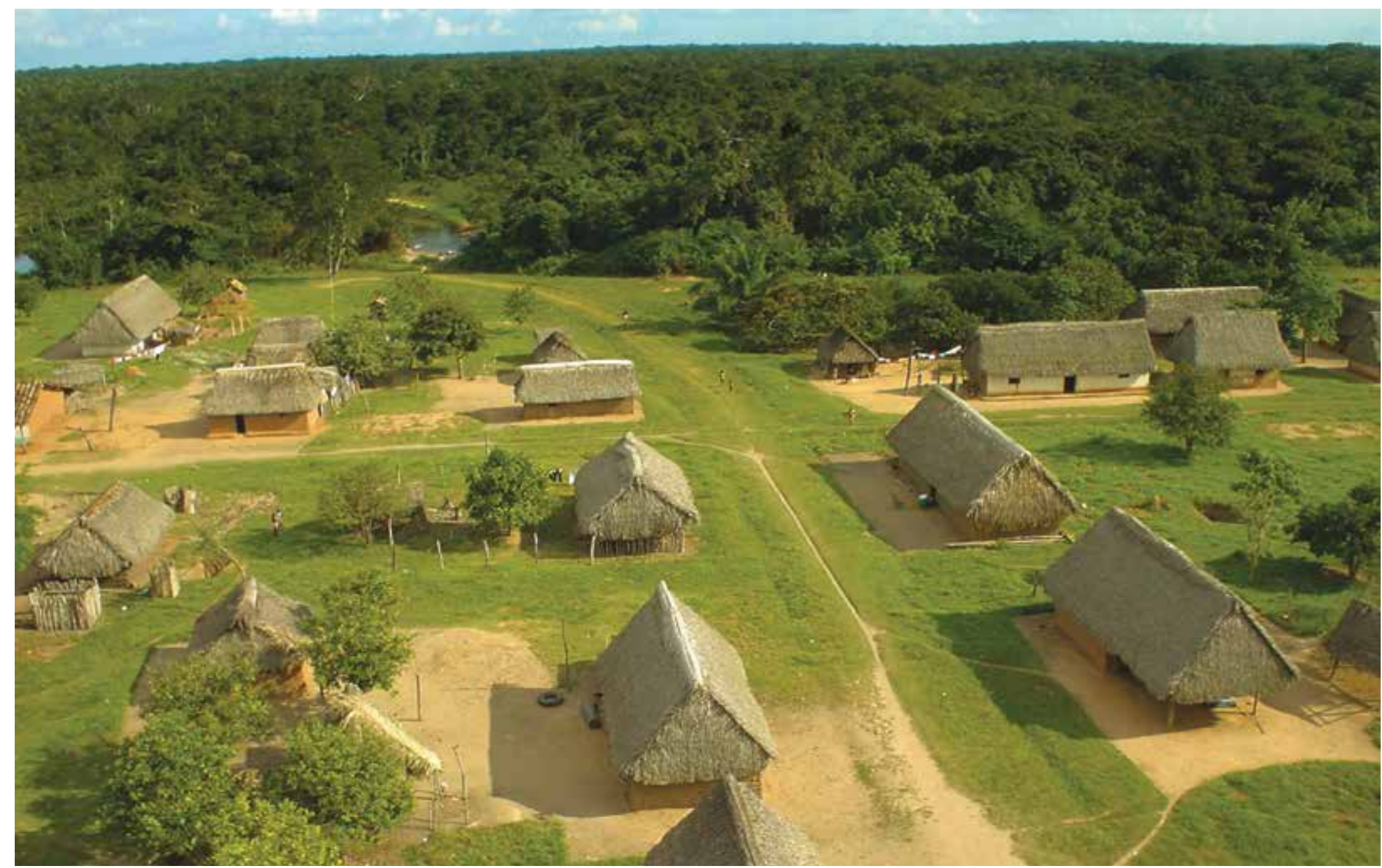

Because we truly believe that the best way to learn is by doing, we jump right in with suggestions on how to begin doing ACM. We detail specific steps to give a clear picture of how to start ACM. However, we do not want you to follow these steps blindly. Adapt them as you go along. Discover what works for you and your community!

4 Field guide to Adaptive Collaborative Management and improving women's participation
This handbook is just a starting point. As you explore ACM, you will have many questions, and other handbooks, books and websites can help you to learn more about ACM. See the "Additional resources" section at the end. 


\section{Understanding ACM}

This section provides you with a definition of ACM, a look at ACM and women's participation, a description of how ACM has been applied in various contexts and a brief history of ACM. If you are new to ACM, it will provide you with a conceptual foundation, which will be necessary for understanding and facilitating ACM in the community. If you are already familiar with ACM, you may find useful perspectives here as well.

\subsection{Basic definition of ACM}

ACM is a conscious effort to learn and act collectively to systematically adapt to change and improve management outcomes.

Here is a breakdown of the elements of ACM:

Adaptation is change in response to a new situation. The new situation could be environmental change, a new opportunity or a problem. Forests and communities are complex and constantly changing. While we may find it useful or necessary to make management plans, we must be prepared to adapt and change those plans. Effective adaptation to change requires that we learn systematically from our own experiences. That means that we need to observe what is changing, try to understand how and why it is changing, and then discuss what actions we should take.

Collaboration is a process of working together toward a shared goal. Resource management involves multiple actors, and intentional efforts to collaborate are more likely to generate positive outcomes.
Sometimes, this means finding enough common ground around problems that can be solved without getting hung up on points of conflict that cannot be resolved. By collaborating, combining knowledge and learning together, local people and other actors are much more likely to achieve management outcomes together.

Management means taking intentional actions to bring about a desired outcome in the future. While it is not possible to predict the future, especially in the complex environments of forest communities, it is possible to plan and prepare for it.

Another important concept in ACM is social learning. Social learning happens when community members and local actors

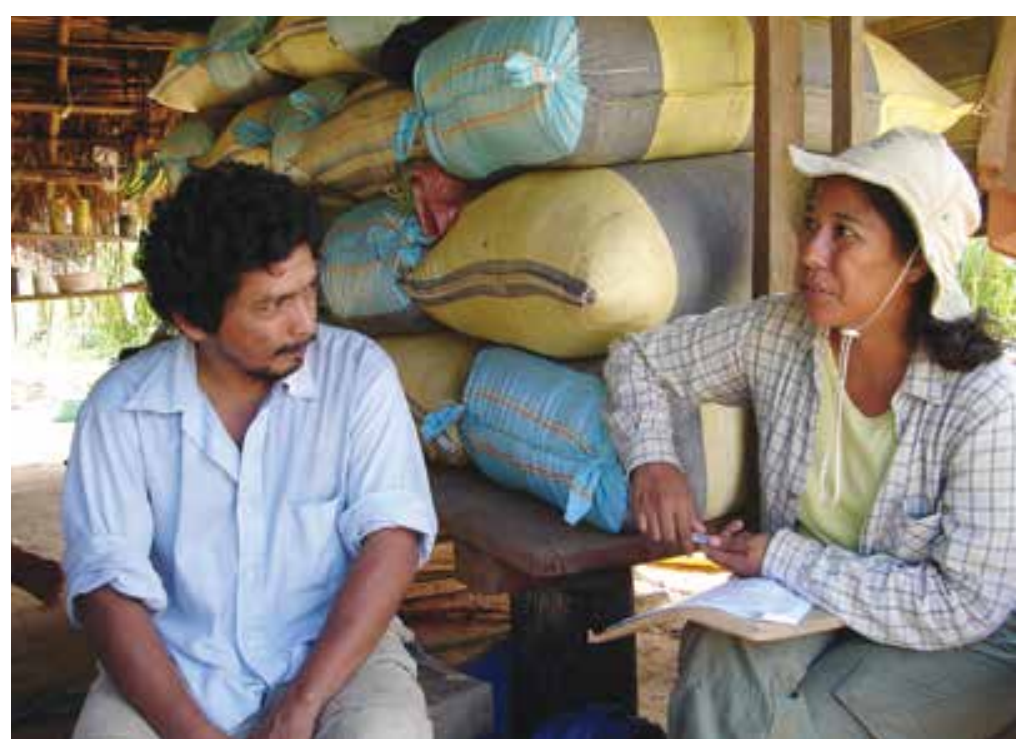



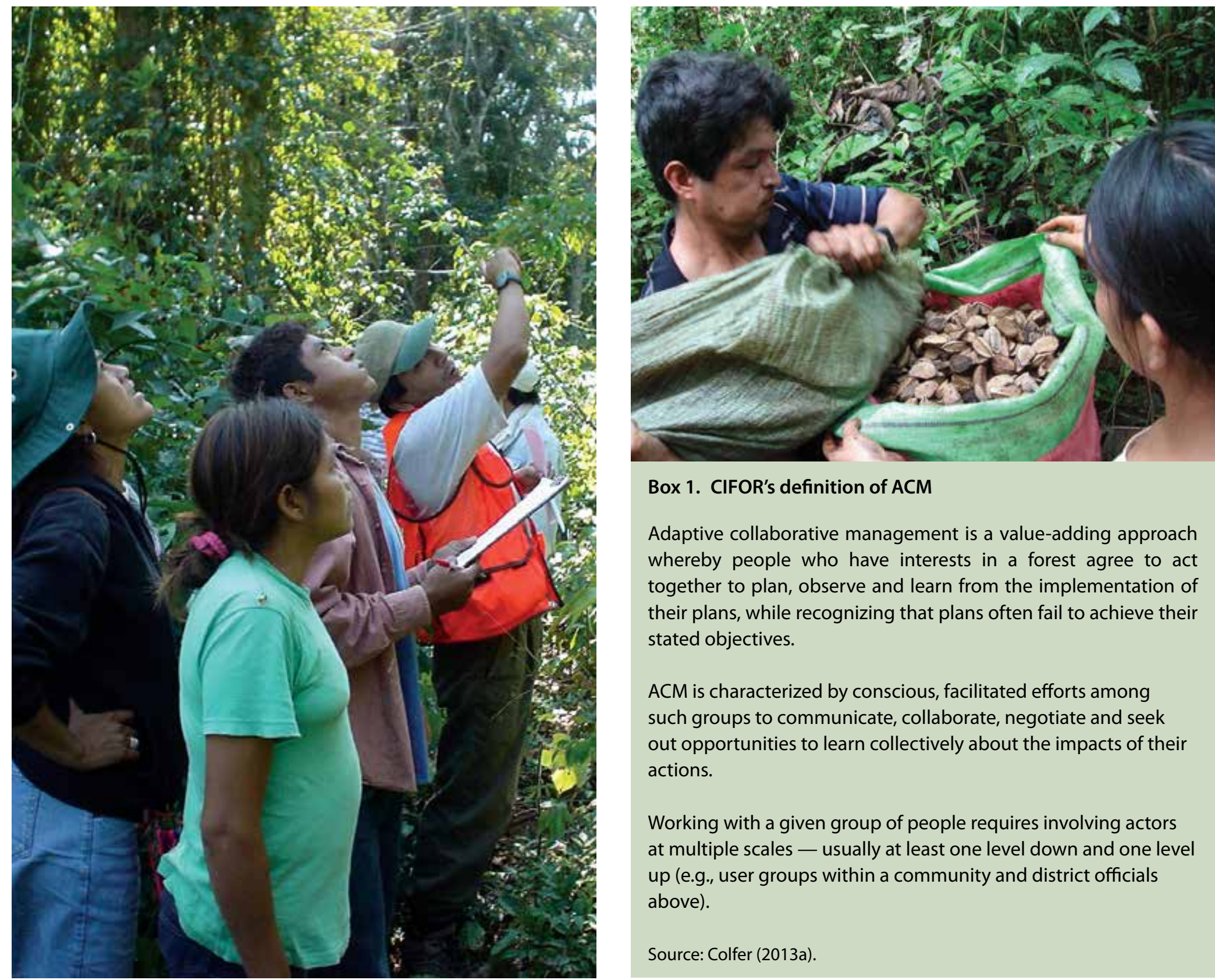

Box 1. CIFOR's definition of ACM

Adaptive collaborative management is a value-adding approach whereby people who have interests in a forest agree to act together to plan, observe and learn from the implementation of their plans, while recognizing that plans often fail to achieve their stated objectives.

ACM is characterized by conscious, facilitated efforts among such groups to communicate, collaborate, negotiate and seek out opportunities to learn collectively about the impacts of their actions.

Working with a given group of people requires involving actors at multiple scales - usually at least one level down and one level up (e.g., user groups within a community and district officials above).

Source: Colfer (2013a).

6| Field guide to Adaptive Collaborative Management and improving women's participation 


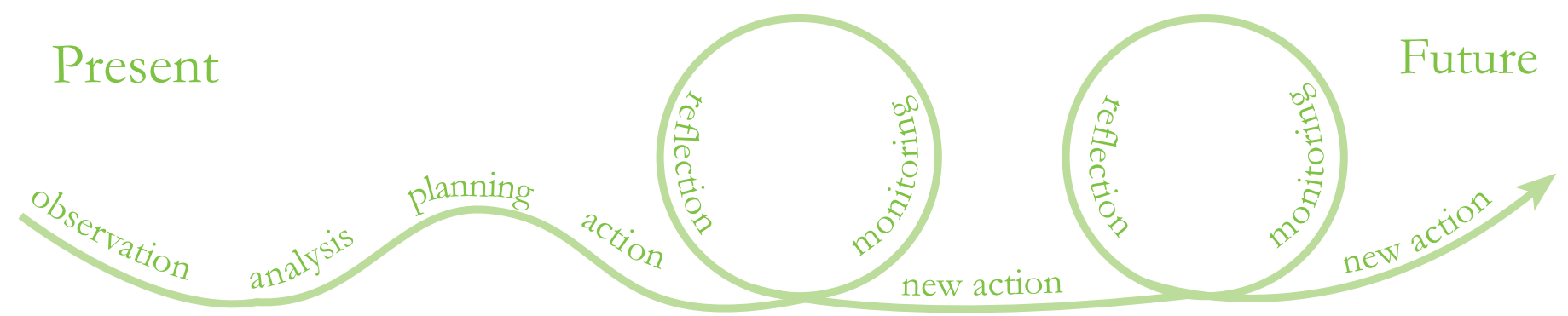

Figure 1. The ACM "worm" shows how systematic learning helps us adapt to change (adapted from Colfer 2005a).

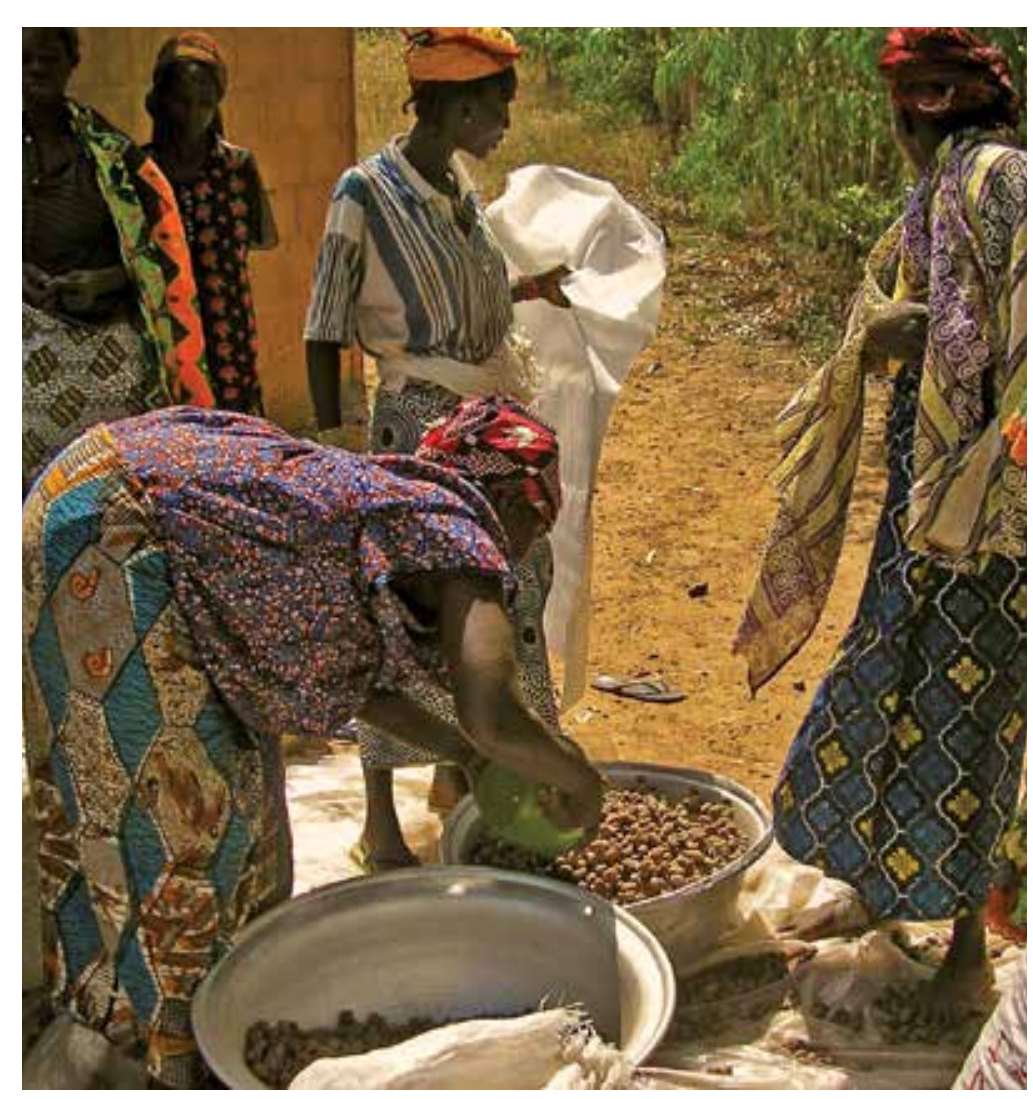

Photo by Daniel Tiveau engage in learning by doing together. The process is improved by explicitly sharing observations and discussing them as a group.

Social learning in ACM can be thought of as a cycle, sometimes called the "worm". The worm shows how ACM creates an iterative learning cycle through a process of planning, taking action, monitoring and reflecting on the process.

\subsection{ACM and women's participation}

We wrote this manual based on our experiences using ACM to improve women's participation in decision making about their community forests. When we started our work in Nicaragua and Uganda, we chose ACM as the most appropriate method for creating new spaces for women to participate. We hoped that by empowering women and helping them define a common agenda based on shared experiences, they could gain the skills and selfconfidence necessary to increase their participation and do it on their own terms.

Greater participation by women does not just happen on its own. It is a complex process that is dependent on the many elements that define gender - including culture, practice, economic factors and 


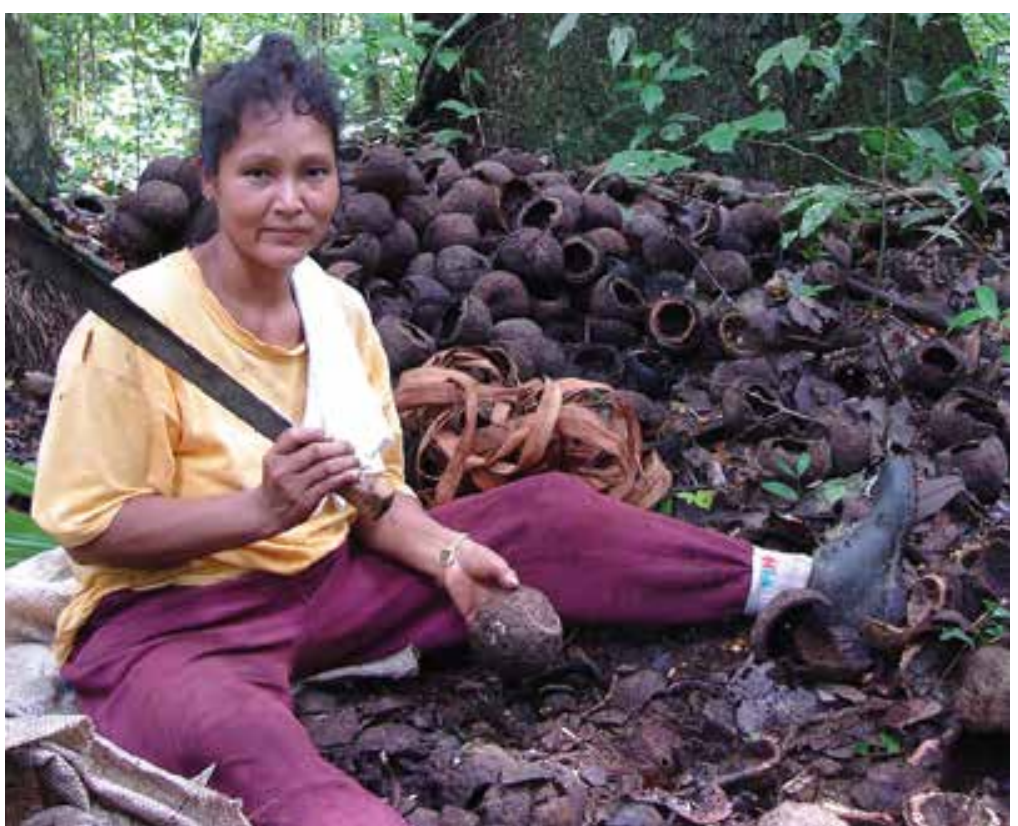

political climate - and on the individual personalities involved. Therefore, the ACM team must make a conscious commitment to introduce discussions on gender and participation consistently throughout the process. Such discussions must always be contextspecific; facilitators must be aware that gender relationships and norms mean different things in different places. Throughout this manual, we provide examples and suggestions of how you might do this.

For a deeper discussion of gender and its many dimensions related to forest management, we recommend The Gender Box: A Framework for Analysing Gender Roles in Forest Management (Colfer 2013b) and Integrating Gender into Forestry Research: A Guide for CIFOR Scientists and Programme Administrators (Manfre and Rubin 2013). See the "Additional resources" section for more information.
In Zimbabwe, the ACM team used "Training for Transformation" (Paulo Freire's approach) to help women overcome theirfear of participating (Mutimukuru-Maravanyika and Matose 2013). In Indonesia, in Jambi Province, ACM facilitators used routine reflection meetings during which women became skilled at speaking up, working together and leadership (Kusumanto 2007).

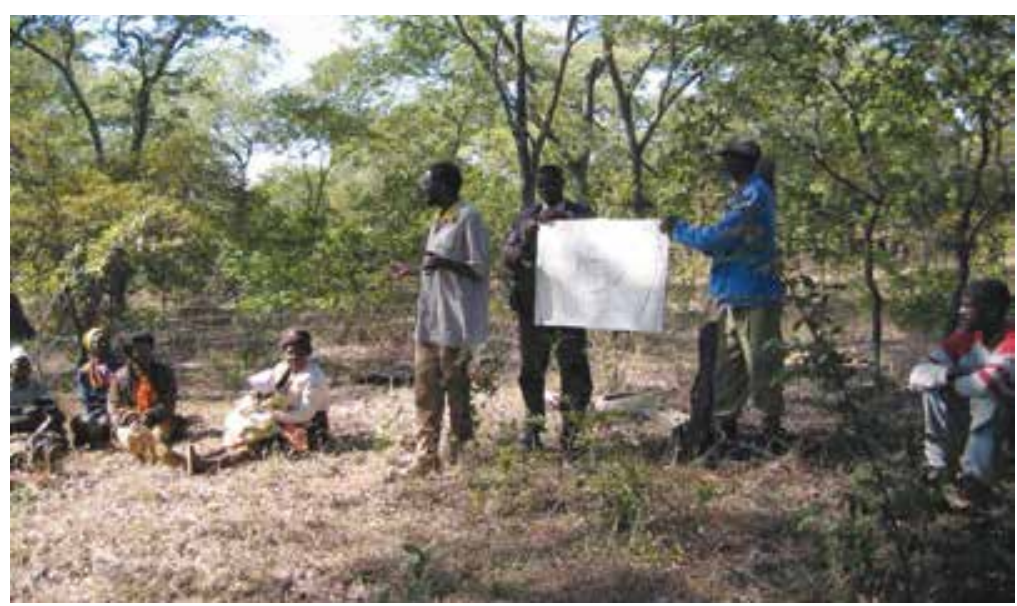

Photo by Abdon Awono

\subsection{More ACM applications}

ACM has also been used to address problems related to resource governance, sharing/distributing the benefits from resources, improving or strengthening voice and collective action in order to achieve the following:

Manage natural resources to meet people's needs better, and learn intentionally to avoid the pitfalls of blind trial-and-error learning. 


\section{Box 2. ACM and gender in Nicaragua and Uganda}

In Nicaragua, forest land recently titled to indigenous peoples was being brought under community management, but women were not being included in the decision making. Through the planning and implementation of small-scale ACM-based projects - tree nurseries, reforestation, establishment of rules - the participation of women and forest governance improved. Through the process, the ACM team uncovered several local sensitivities to projects that focus on gender in indigenous communities:

- The roles of women and men in communities and the forest are interwoven and diverse. Delineating roles along male/ female lines may result in an oversimplification of the existing conditions and miss the complex realities.

- Some local women leaders argue that women already play a substantial - yet under-recognized - role in forest management, and efforts should be made to make people aware of that participation. Basing ACM approaches on initial assumptions that women's roles are minimal may serve to marginalize or further obscure that participation.

- An ACM project that is perceived to focus on women and exclude men will not get the necessary buy-in and support from men, which will limit its effectiveness and credibility in the community at large.

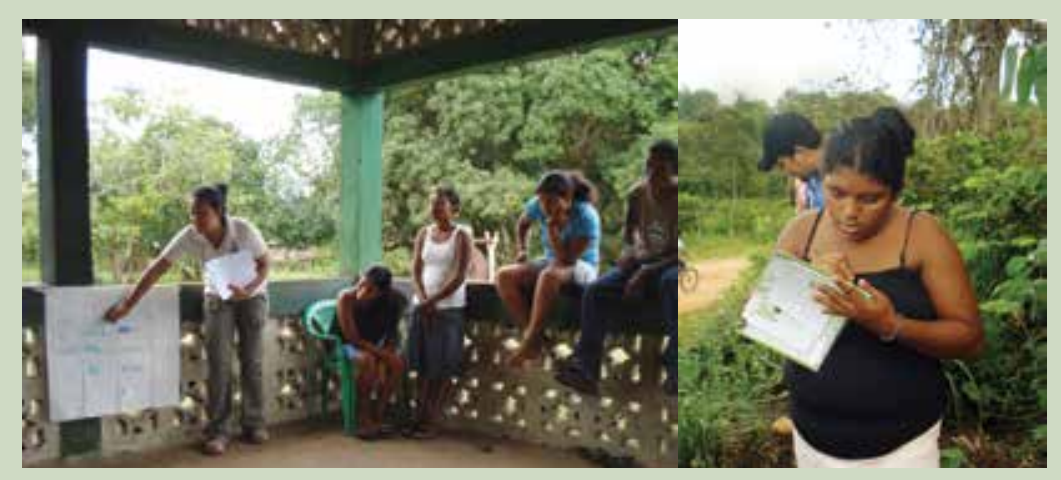

Our Ugandan team found that if men foresee tangible benefits from women's participation, such as increased household income, they are more likely to support it. In Uganda, the ACM team saw these results:

- Increased participation of women in tree planting. In some communities, cultural norms do not allow women to plant certain tree species. Through ACM, men and women shared their fears and concerns about the practice, and recognized that tree planting by women could benefit the entire family. Now some women have their own plots and have planted income-generating trees such as eucalyptus, pine and Maesopsis spp., and men are attending ACM meetings with their wives.

- Increased number of women in decision making positions. Through ACM, both men and women came to realize that it was important for women to take up decision-making positions, and now older women have assumed leadership roles. Younger women have yet to move into leadership positions.

- Participation of women in meetings and discussions. Initially, women were timid and contributed less but now they contribute equally, depending on the topic. Although older men and young men still tend to dominate discussions, women are progressively gaining ground. If the topic was firewood species, handicrafts or medicinal herbs, the women contributed more. If the topic was land/tree tenure and trees for income, men contributed more.

- Interest in participation in group activities. Women have shown growing enthusiasm for engaging in tree nursery operations, monitoring, training, beekeeping, study tours, community forest management and other group activities.

- Increased confidence. Initially women would not express their opinions or were too timid to speak up in meetings. Now, women raise their hands, contribute to the discussions at hand, and express the constraints and their expectations and fears about tree planting even in the presence of men. They even volunteer to take up responsibilities of leadership. 
For example, in Zimbabwe, broom grass was being unsustainably harvested in communities for commercial sale, generating conflict and mistrust and threatening the resource base. ACM provided a way for all of the actors involved to understand the problem and change their decision making and management (Nyirenda and Kozanayi 2007).

Empower local people by increasing their ability to think in a more profound way about long-term forest use and achieve management objectives.

In Bolivia, indigenous communities managing their forestry enterprises were troubled that they had no profits from their forestry activities to invest in community projects. Through ACM, they evaluated their wage structure and changed it to make it fairer and to generate funds to build two community wells (Cronkleton et al. 2006).

Improve participation by other marginalized groups, such as ethnic minorities, in decision making and benefits.

In Nepal, the ACM team was able to make measurable progress toward more effective involvement of both women and other marginalized groups by explicitly discussing justice and equity - a process strongly supported by the Forestry Ministry (Dangol 2005).

Address conflict by providing opportunities for parties in conflict to create solutions together.

In one forest village in Uganda, ACM helped community members - men, women and youths - improve their negotiation skills, which helped them establish an agreement with private forest owners to co-manage parts of their forests.

\subsection{Where ACM came from}

ACM came from our recognition that management of natural resources requires constant learning, adaptation and collaboration. It also must involve local people in a meaningful way. The interaction of forests and people is a very complex system, with connections and feedbacks that we do not completely understand. Outside forces such as agricultural frontier expansion, climate change, globalization and surprise events such as hurricanes and floods pose challenges for communities. In a complex, changing world, it is difficult to know how you can plan ahead for two years, five years or 20 years.

We have learned that many natural resource management efforts have been failing because they do not include local people in decision making or do not recognize their key knowledge, values and capabilities. Conversely, many "participatory" initiatives have fallen short of their promise mainly because they did not put enough emphasis on learning (Cooke and Kothari 2001; Colfer et al. 2011). For local communities to participate effectively in decision making, they must be involved in learning and knowledge creation. This is particularly the case with groups such as women, the elderly, youth and ethnic minorities, who may have been excluded from these processes for a long time and may either feel that they do not know enough to participate or that their knowledge is not valued by others.

A new management approach that emphasized participation, learning systematically and adapting to change was needed. In the late 1990s, CIFOR scientists and others looked at adaptive management systems that were evolving in the Pacific Northwest of the United States (Lee 1993). They took those ideas as well as other concepts and integrated them with participatory action research (PAR) approaches. PAR approaches were developed in the 1960s and 1970s in South Asia and other parts of the world to democratize knowledge making and ground it in real community needs (Borda and Rahman 1991). PAR combines local knowledge with expert knowledge through hands-on collaborative experimentation and social learning (German et al. 2012).

So, as you can see, while ACM may seem like a new idea, it is based on the experiences and knowledge of many communities and experts from around the world.

10 | Field guide to Adaptive Collaborative Management and improving women's participation 


\section{Putting ACM into practice}

In this section, we show you how to do ACM step by step. The most successful ACM plans involve specific short-term activities that can be completed successfully and evaluated as a group, while working toward a long-term goal. Indeed, you might think of $\mathrm{ACM}$ as a journey of many small steps (Colfer 2007).

ACM does not have to be complicated or costly. The activities may be simple - indeed, it's an excellent idea to begin with something simple, to build up participants' confidence. The most important investment is in the time to discuss, reflect and follow up, making the learning process more explicit. People need that time to learn and grow.

Next we present a suggested sequence of ACM activities. ACM is a flexible, participatory approach that combines community-based workshops and meetings with activities in the field. We encourage you to experiment with the activities as you plan. Try to include field activities as early as possible. While it can be convenient to schedule meetings or workshop activities at the village's school or meeting house, ACM functions through learning by doing, so experiment with meeting outside where people are working and spending time: where people wash clothes, plant crops, collect forest products, fish, etc. Also, you are more likely to attract the interest of a broader cross-section of the community if you vary the rhythm and take the workshops and activities to the people.

We go into more detail for each step in the following sections.

Here are the ACM steps at a glance, with illustrative times needed

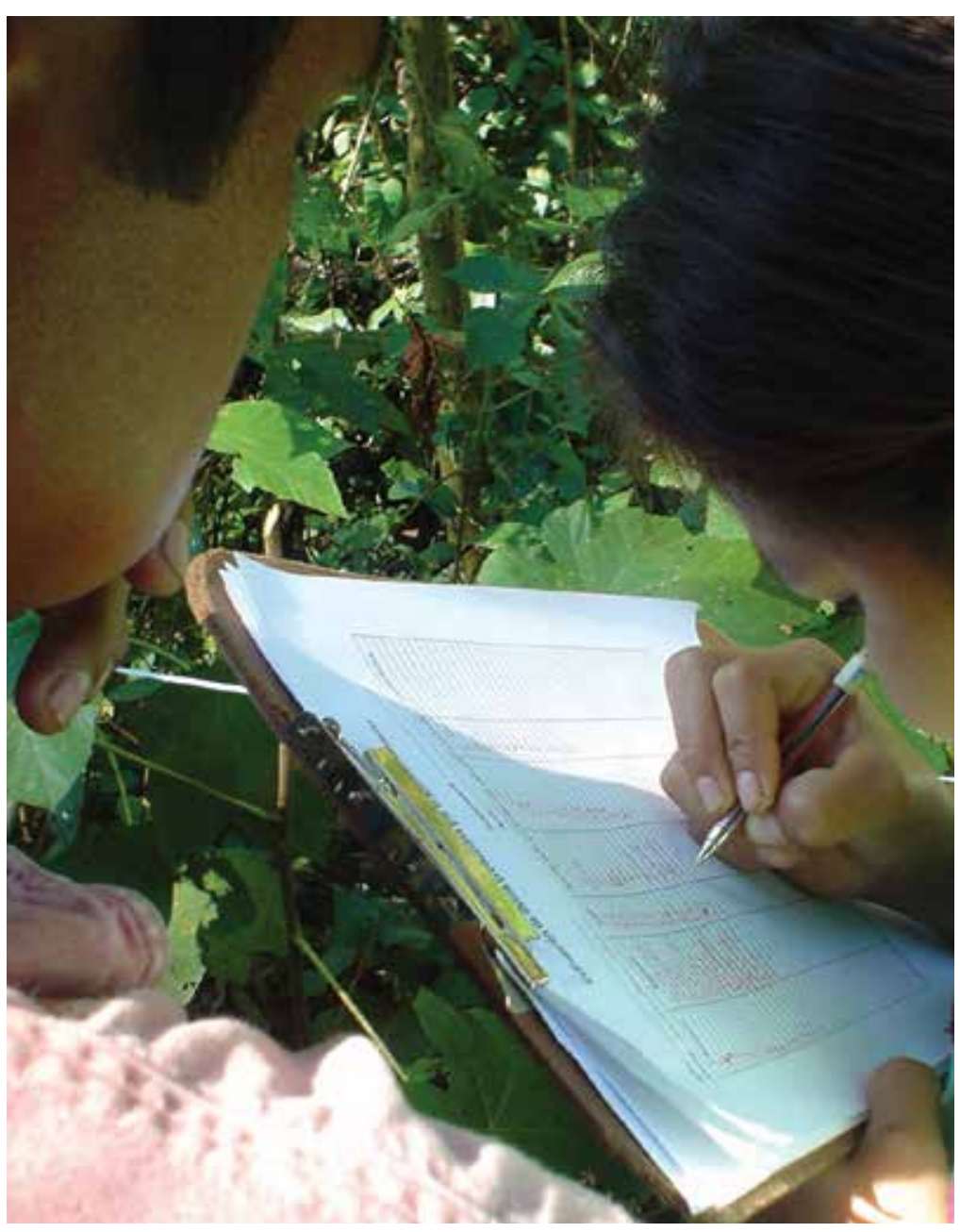
(these may vary): 


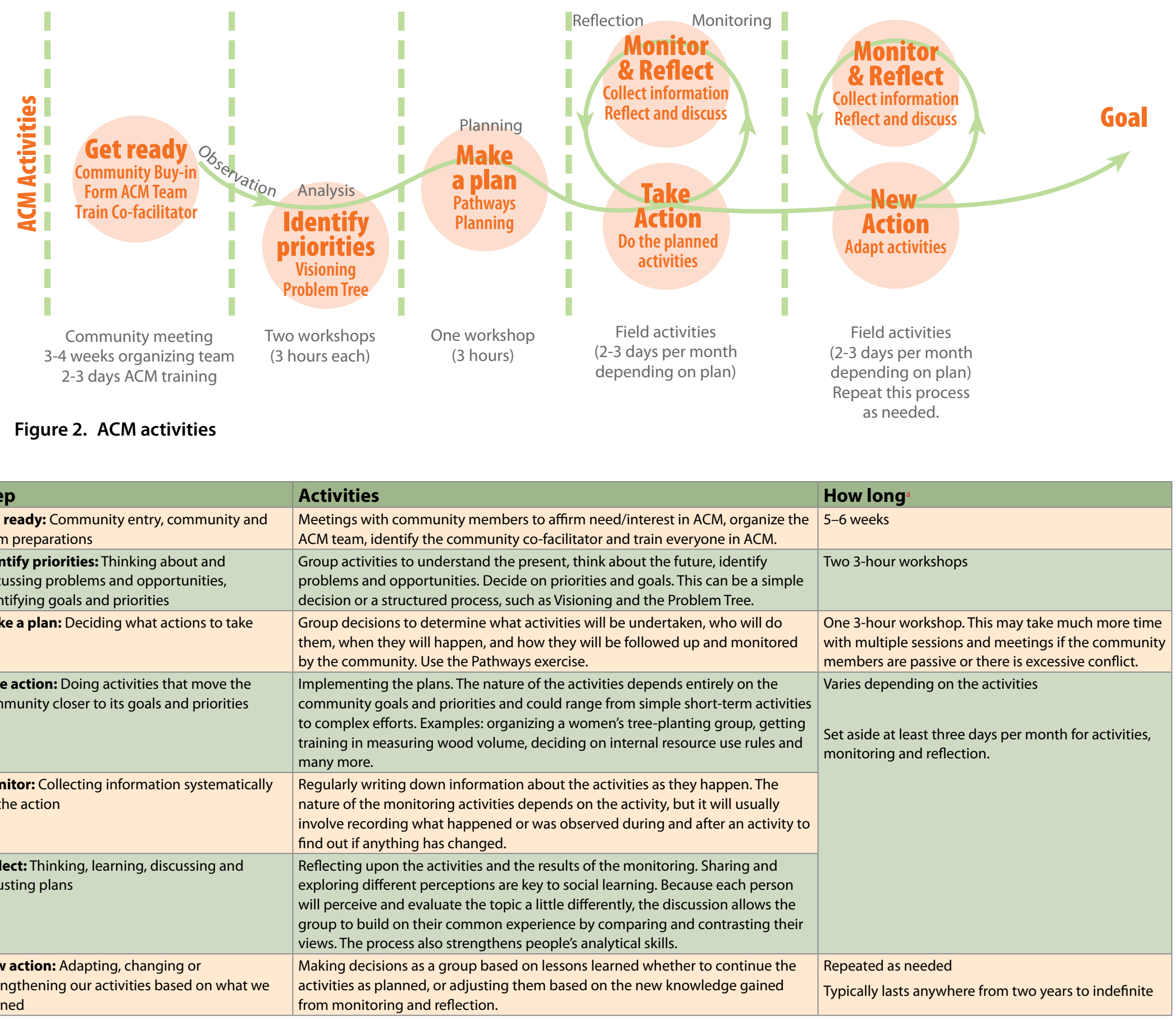

12 | Field guide to Adaptive Collaborative Management and improving women's participation 


\subsection{Get ready}

\subsubsection{Deciding to do ACM}

Keep in mind that a deeper understanding of ACM comes with putting it into practice! However, some general knowledge is crucial before work begins, for community members to make informed decisions and to get buy-in from the community in general.

Make a presentation about ACM in a general meeting or to community representatives. ${ }^{2}$ Consider going house-to-house too - many people, often women and young people, do not come to community meetings. Create a one-page flyer with the key points to distribute. It is easy to get bogged down in concepts, so try to present as many examples and drawings as possible. Use examples from this manual to help. Explain things in your own words, and make sure you translate the concepts into the local language.

Here are suggestions for topics for the presentation.

- Basic definition of ACM: "ACM is a collective problemsolving and learning method. Everybody can participate, contribute their knowledge and learn together how to solve important problems. It focuses on learning - from our mistakes and our successes.” Again, use your own words and translate it into the local language.

- Explain the steps of the "worm". Accompany the worm with visual and graphic images, not technical ones, describing the activities at each step. Use examples (Hartanto et al. 2003).

- Emphasize that the community decides on its priorities and plan of action (Colfer 2013a).

\footnotetext{
2 If this is the first time that you are working in a community and with the members of that community, you will need extra time at the beginning to get to know the individuals, relationships and the context and to do an initial
} baseline analysis.

\section{Box 3. Spreading the ACM knowledge}

On the east coast of Nicaragua, the ACM team held a fourday ACM training workshop in the regional capital for two members from each interested community. On the final day, the participants assumed the role of facilitators and practiced giving ACM workshops to the regional territorial leaders, who were in the city at the time for a different event. This created a foundation of understanding and interest in ACM early in the process.

- Reflect with the group: Do they see issues of concern in the community that ACM might help them address? Are there challenges ahead that ACM can help them plan for?

If the community members decide to move forward, it is time to get started with ACM!

\subsubsection{Forming the ACM team}

ACM is a team effort. It involves close collaboration and support of a multidisciplinary outside facilitation team and a community counterpart, whom we refer to here as the co-facilitator.

The facilitation team should be made up of neutral actors who can focus on strengthening the roles of local people to create a more level playing field. A strong team will have men and women with backgrounds in both the natural (forestry, biology, etc.) and social (sociology, anthropology, education) sciences, with the ability to communicate in the local language. Facilitators must be able to make frequent visits to the community to organize workshops, go along to activities, encourage participation and support conflict resolution. In reality, the facilitation team will probably be selected by whatever entity is spearheading the ACM work, such as an NGO, research institution or government agency. 


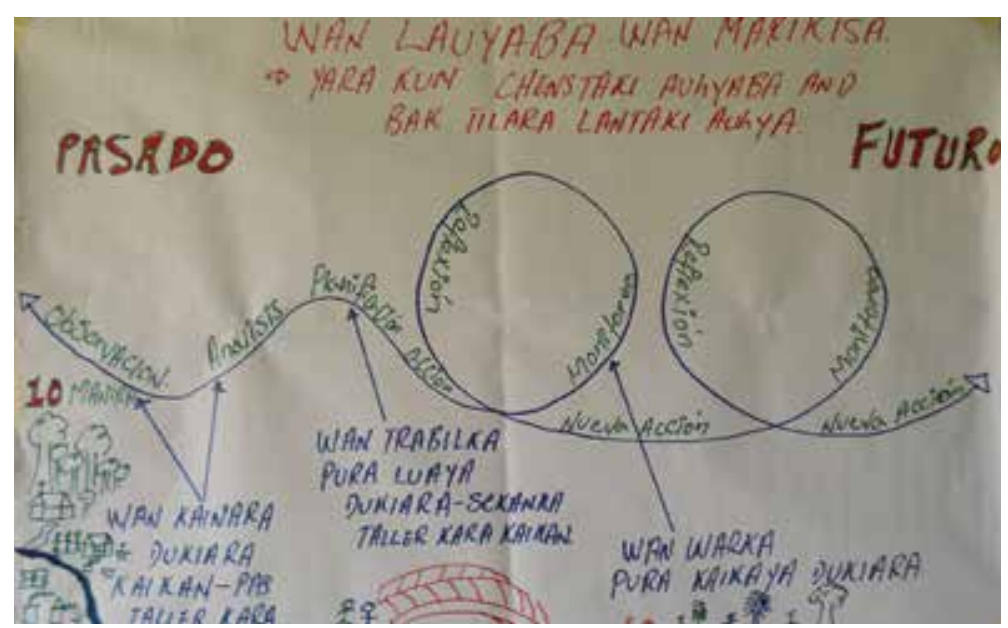

The "worm," translated into Spanish and the local language.

TIP: You should refer to ACM concepts like the "worm", and versions of them, many times during the course of your ACM work in the community, not just at the beginning. Revisit the concepts in meetings and in the field. You might make a diagram showing the steps, which you leave on a wall in your meeting place. Adjust and update your examples as you learn with the community members. It is worth it! Every time you do, understanding will deepen and spread.

In the early days, the ACM facilitators will focus on facilitating the ACM process, but over time their roles change and they become mentors offering support, guiding and accompanying the process, and encouraging reflection and learning. In situations where government service providers are facilitating the ACM processes themselves, they will continue to take different roles over time, sometimes going back to facilitation if new challenges emerge.

The community co-facilitator (or community liaison or partner) plays a crucial role. She or he is a member of the community.

\section{Box 4. Money and incentives}

In CIFOR's ACM programs, we have tried very hard to give no monetary incentives (although we did not completely succeed). Mostly our incentives were training opportunities, cross-visits to other places or perhaps tea at meetings. In some cases there was a pot of money on which community members could draw for specific actions, to "prime the pump".

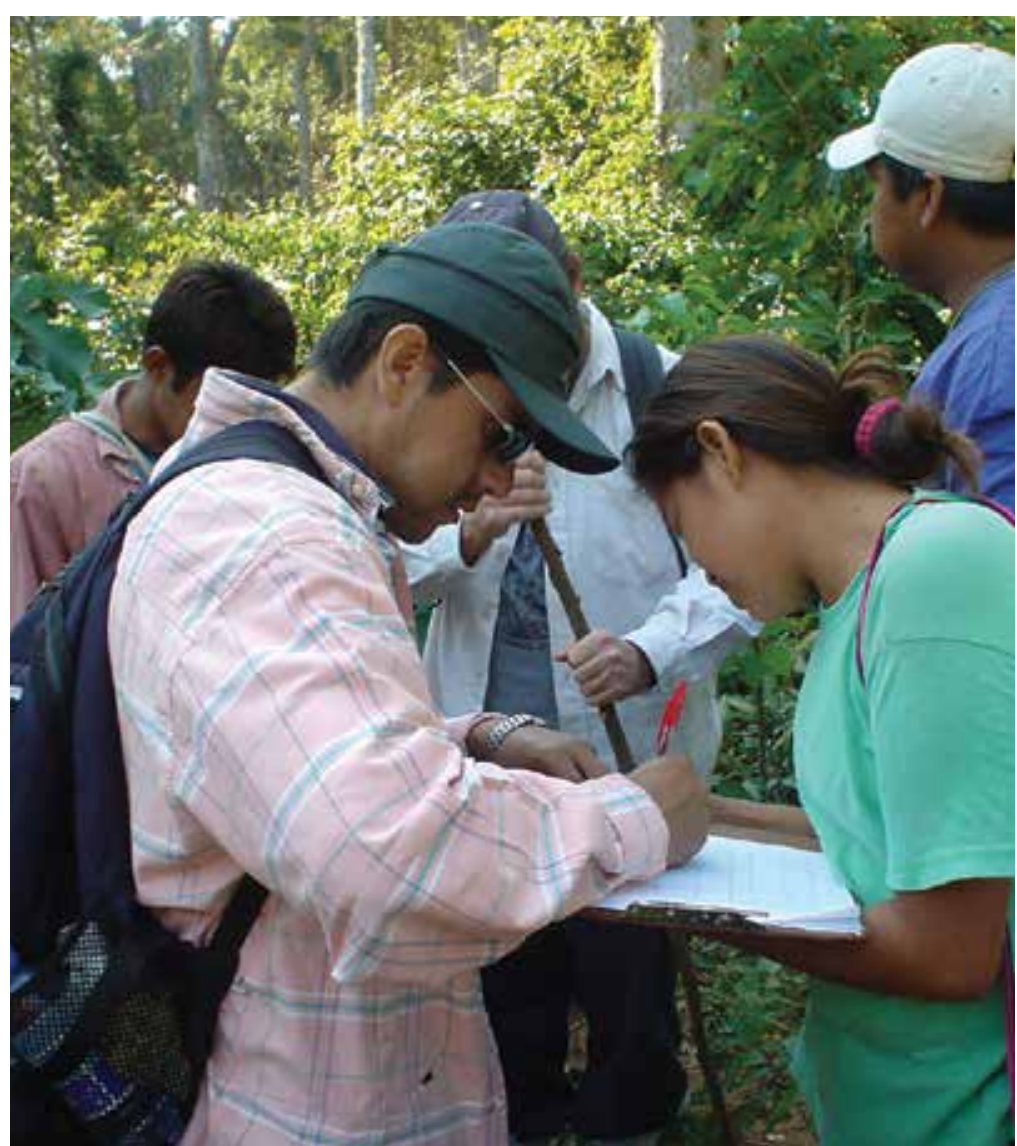




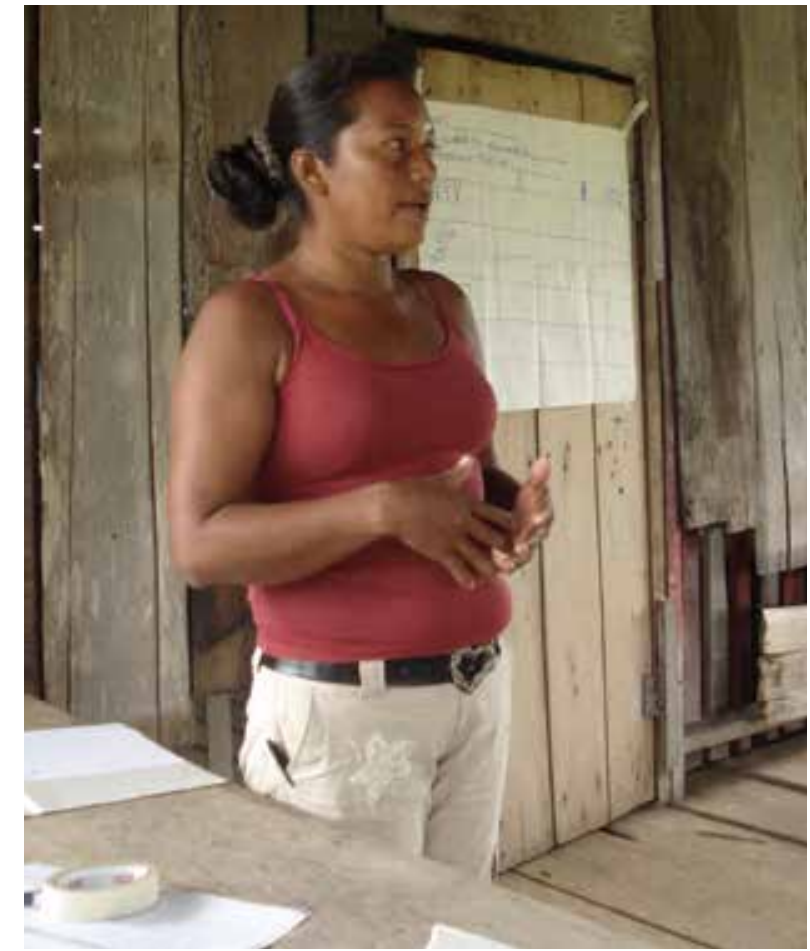

In Nicaragua, the co-facilitators helped run workshops and follow through on activities with community members.

She serves as your key ACM counterpart in the community and is responsible for helping you carry out the ACM project and activities. The co-facilitator should be encouraged to take ownership of the process and to play a role in all steps. By investing in your co-facilitator(s) and making her a true partner in the process, you will be building capacity in the community, which is crucial for the sustainability of processes in cases where outside facilitators are involved; these will inevitably pull out of the process eventually.

A co-facilitator should have the respect of the community, leadership skills and the ability to recruit and encourage

\section{Box 5. Always new participants}

A challenge that ACM facilitators often face is that there are new participants in the workshops and activities every time, requiring repetition of material. This is inevitable. Rather than get frustrated, count it as a great opportunity to introduce new people to ACM. Always do a 10-minute review of ACM concepts at the beginning of every workshop and activity, and recap what you have done to that point (better yet, have your co-facilitator present this). Ask anyone who has participated in the previous activity to help make the presentation. This repetition also serves to reinforce ACM concepts to those who have heard it already.

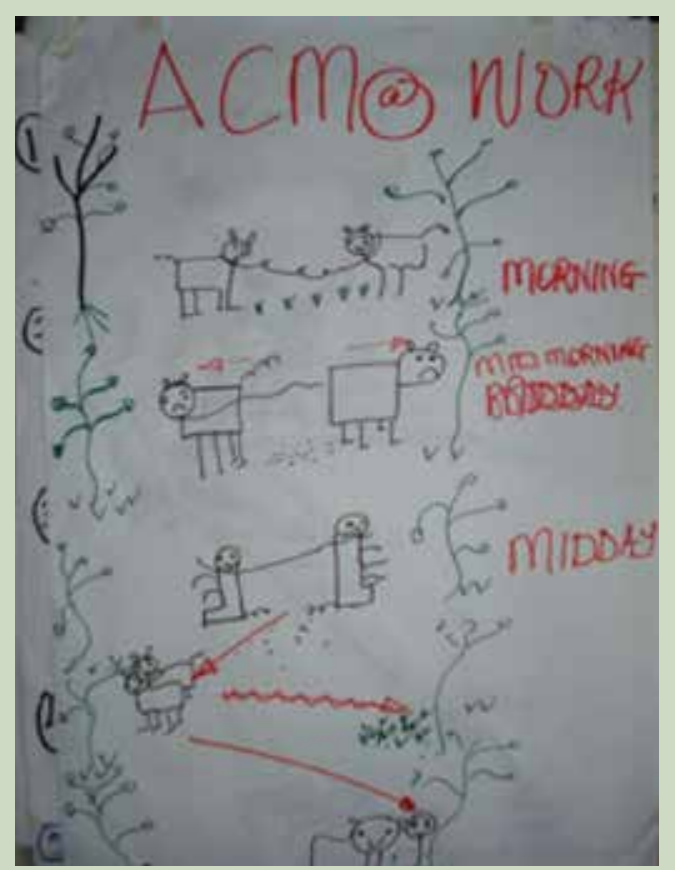

The Ugandan team explored ways to relate ACM to daily life. They came up with the story of two goats that had to learn how to collaborate in order for both to benefit. 
participants. She/he must be able to attend workshops, travel outside the community and be interested in leading activities. Think carefully about what incentives — such as payment for her/his time - may be appropriate, and how those incentives should be handled, especially when outside help is withdrawn.

Consider co-facilitators who are not already in leadership positions. Leaders often have too many commitments as it is! However, make sure that the selection of the co-facilitator is acknowledged and validated by the community leaders. Consider asking the co-facilitator to recruit and train an assistant cofacilitator. That will make her job easier. ACM projects can last for years, and circumstances may change for your co-facilitator that may preclude her from participating for the entire length of the project. Also, it is not always possible for the co-facilitator to be present at activities. Involve the assistant as much as possible.

Spend several days training the co-facilitators in ACM concepts and methods. This will sharpen your own facilitation as well as providing needed exposure for your co-facilitators to be able to take an active role in the process.

Both the external facilitator and the community co-facilitator should remember the importance of modesty - that they are not in charge of solving the community's problems, but rather serve as a catalyst to help community members solve their own problems.

\subsubsection{Planning the ACM activities}

Careful planning is crucial to running workshops and activities that are productive, energetic and participatory. ACM projects take time. Make sure that you can dedicate the resources necessary not just for the workshops and monitoring, but also for the all-important informal conversations in the field, at work and in homes, as well as other types of follow-up.
Make sure that you have a mix of skills, information, activities and reflection. Be prepared to ask questions of participants frequently. Prepare your questions ahead of time.

\subsubsection{Identifying participants}

Determining who participates in the ACM activities - as well as who decides who participates - can be a very sensitive issue. Communities, no matter how large or small, are complex. Relationships, hierarchies, power and personal histories all affect the outcomes of management activities. Acknowledging and understanding this complexity is important when working with communities. It is important to take the time to consult with as many local people as possible, from both inside and outside the community, to understand the context and the range of people who are affected by the relevant issues and should be invited to participate.

We suggest performing a "stakeholder analysis" before engaging in ACM. Effective tools for identifying stakeholders and their relationships can be found in the "Additional resources" section (Colfer et al. 1999; Sithole 2002; Wollenberg et al. 2005).

\subsubsection{Encouraging and sustaining the participation of women}

ACM can encourage women and other commonly excluded groups — such as youth, older people and ethnic minorities — to participate more fully in activities and planning related to natural resources.

Encouraging women's participation requires conscious effort. Community members, particularly the most marginalized, may initially be hesitant to participate in ACM activities. Working in small groups, using drawings, individual voting and games that are active may motivate people to participate. 
Someone who is quiet in large group discussions might be good at drawing, or a participant who does not know how to read or write might be the most effective speaker in group presentations.

See the section "Gender and ACM" for more discussion and suggestions.

\subsubsection{Forming resource user groups}

Some ACM teams have found it useful to ask community participants to organize themselves into "resource user groups" by interest. For instance, those people who harvest a non-timber forest product, "broom grass" for example, form one group; those concerned with "timber" form another (MutimukuruMaravanyika and Matose 2013). This can be particularly useful in larger communities. However, groups can end up being exclusive; for instance, the timber group could consist of only men. You can make rules that each group must have a certain percentage of each gender, or other characteristics, to maintain inclusiveness. It is important to remember that women's voices are not often heard.

\subsubsection{Note taking}

Note taking (record keeping, documentation) is one of the most important tools that you will bring to the community. While we all learn from experience, ACM teaches us to learn systematically. That requires writing things down in order to remember what happened and reflect on it.

Your ACM team should include a note taker at all times. You should also train the participants in note taking, particularly during the monitoring activities. Work with the participants to come up with worksheets to fill out for monitoring. Make them simple to fill out. Use symbols, such as the full moon to indicate completion of a planned task, quarter moon for just beginning, and so on (McDougall et al. 2009). Also, avoid using technology that is not

\section{Box 6. Taking ACM to the women}

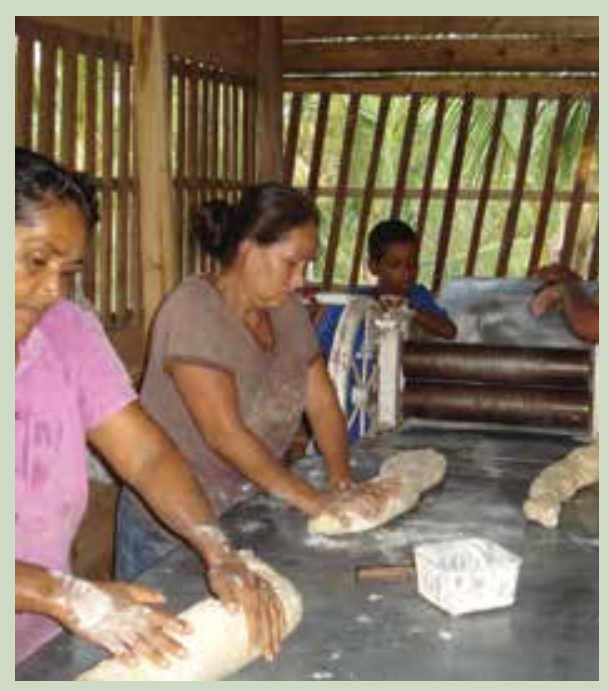

An ACM facilitator in Nicaragua arrived in the community to find that all of the women were busy making bread in the community bakery. He held the workshop in the bakery, thus making it easy for the women to participate. It made sense for another reason: the ACM project involved improving management of the bakery!

In Uganda, the ACM team tried to encourage women to participate in tree nursery activities on site. But the women were more interested in preparing the meal for the group. The facilitator moved to where they were preparing the meal and demonstrated to them how to prepare and pot trees. She then asked each one of them to practice hands-on.

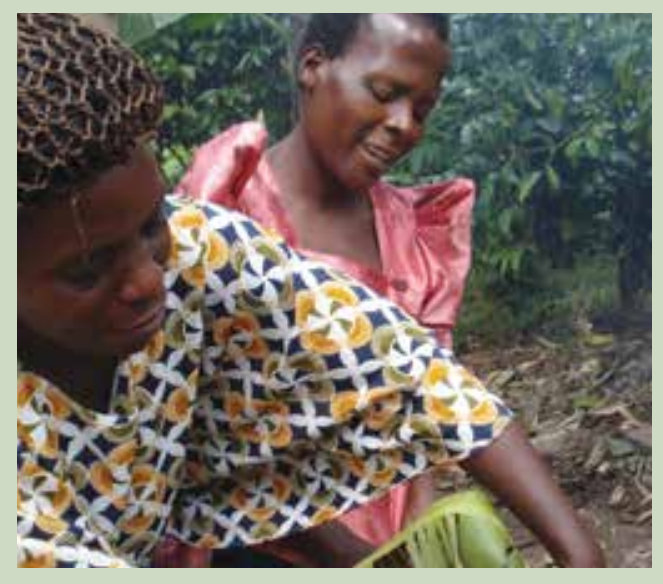


available in the community; for instance, don't use computergenerated worksheets that would require photocopying if there is not a computer or photocopier easily accessible. Teach people how to make new copies by copying them by hand. Consider buying a notebook that serves as the designated monitoring notebook. Format it with the participants. Decide who will be in charge of filing and keeping the notes in a safe place. It is also important for community members to record other things, such as minutes of meetings organized.

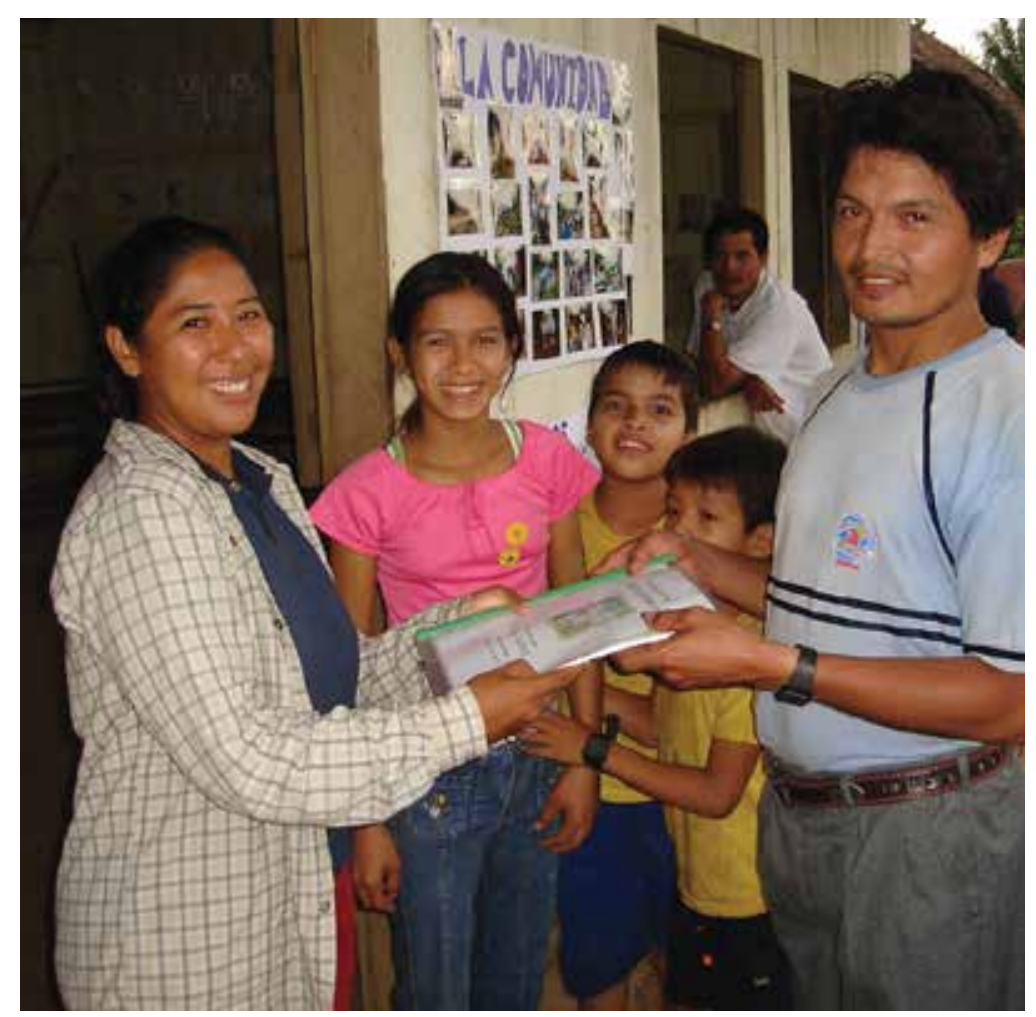

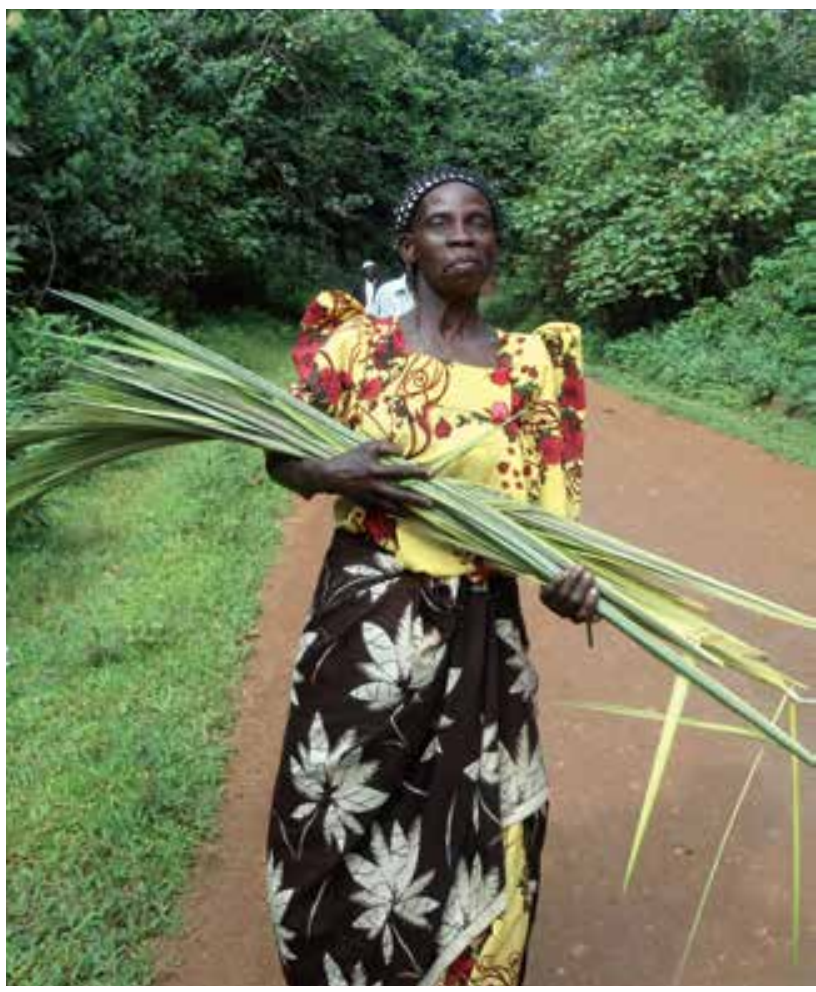

Photo by Concepta Mukasa

Caution! Making rules to enforce gender inclusiveness may meet with resistance from the community members. For example, in Uganda, a forest user group formed sub-groups of resource users including tree growers, grazers, herbal medicine collectors and fishers. However, it is taboo in that community for women to go near fishing areas, so the resource group on fishing is made up of men only. There is no way a rule can force women into that group. Also, in many contexts, strengthening women-only groups can have empowering functions. 


\subsection{Identify priorities}

The first step is for community members to come together to decide on their priorities and identify what issue the ACM project will focus on.

In some cases, there might already be a clear need or application for ACM, or community members have already discussed and decided what their priorities are. They might have already engaged in planning, and might not think it necessary to do all of these activities. However, keep in mind that those decisions might not have meaningfully included women in the process. The results of the discussions, when women's perspectives are included, might bring to light new issues and solutions or head off possible problems. It is also very important to ensure that there is broad community agreement about how the priority issues for ACM are articulated.

There are many methods that you can use to identify problems and priorities. We suggest two here: Visioning and the Problem Tree.

You may use either or both.

\subsubsection{Visioning}

Visioning asks participants to think about what they want their community to look like in the long term and then establish priorities for action based on that common vision. These priorities then serve as the basis for the next step.

\section{Objectives:}

- Empower community members to take command of their future by deciding how they wish it to be in their own terms.

- Get people to think explicitly and creatively about their future expectations and express their views concretely so they can be shared with others.
- Evaluate similarities and differences in visions, explore why they exist and identify common themes and issues in the visions.

\section{Step 1: Decide timeframe and discuss today's concerns}

\section{(1 hour)}

Divide the participants into groups of 5-8 people each. For each group, have a map or photographs of the community area available and spread them out in front of the group. If you have information from your own assessment, provide those results. Start a discussion with the participants about their village today.

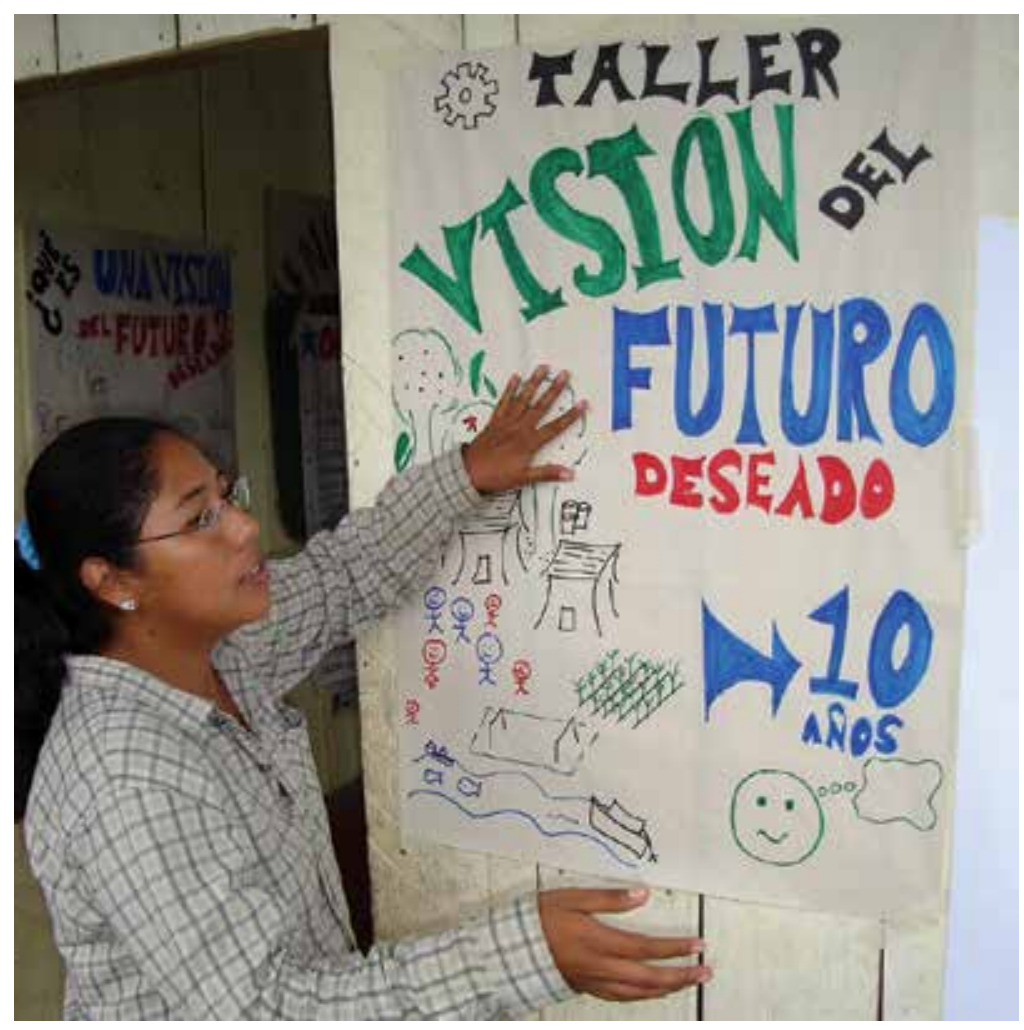




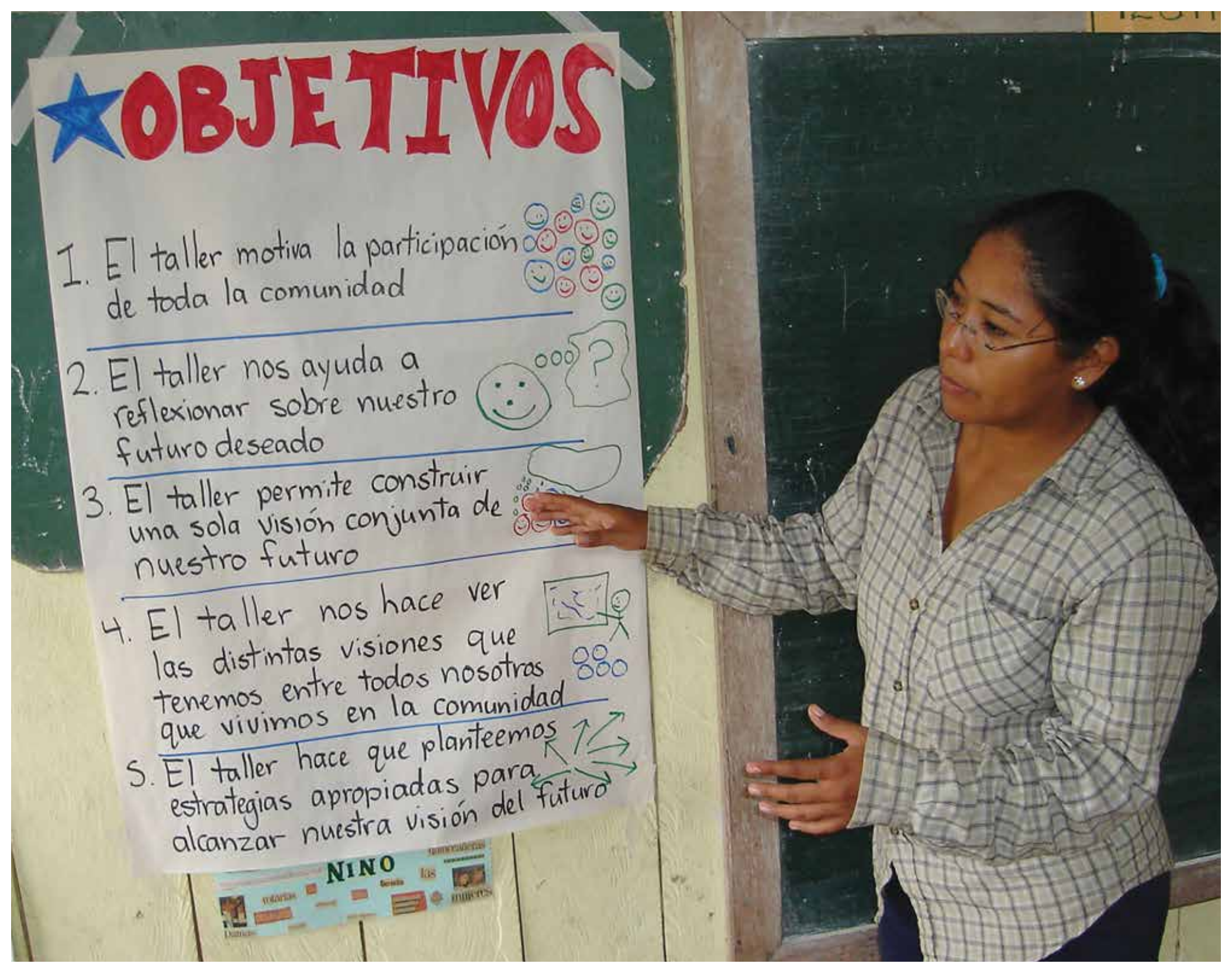

20| Field guide to Adaptive Collaborative Management and improving women's participation 


\section{Identify priorities}

Discussion questions:

- Describe what your community is like today.

- What are the families like?

- What are the land and forest like?

- What do people do for a living?

- What are concerns or problems in your village?

- What would you like to see changed and why?

- What are good things that should not change?

Make sure the note taker is recording the discussions in each group. Alternatively, participants may wish to draw their concerns.
Step 2: Develop the vision of the future (1 hour)

Discuss and decide on the timeframe for the visioning, such as 10 or 20 years. Encourage everyone to relax and think creatively. Tell them to focus on an ideal future, where they have shared goals and aspirations, rather than getting wrapped up in current problems. There are two options for building a vision of the future.

\section{Option 1: A Walk in the Future}

Ask participants to relax, close their eyes and clear their minds. Start them on an imaginary journey into the future. Here is a possible script to start:
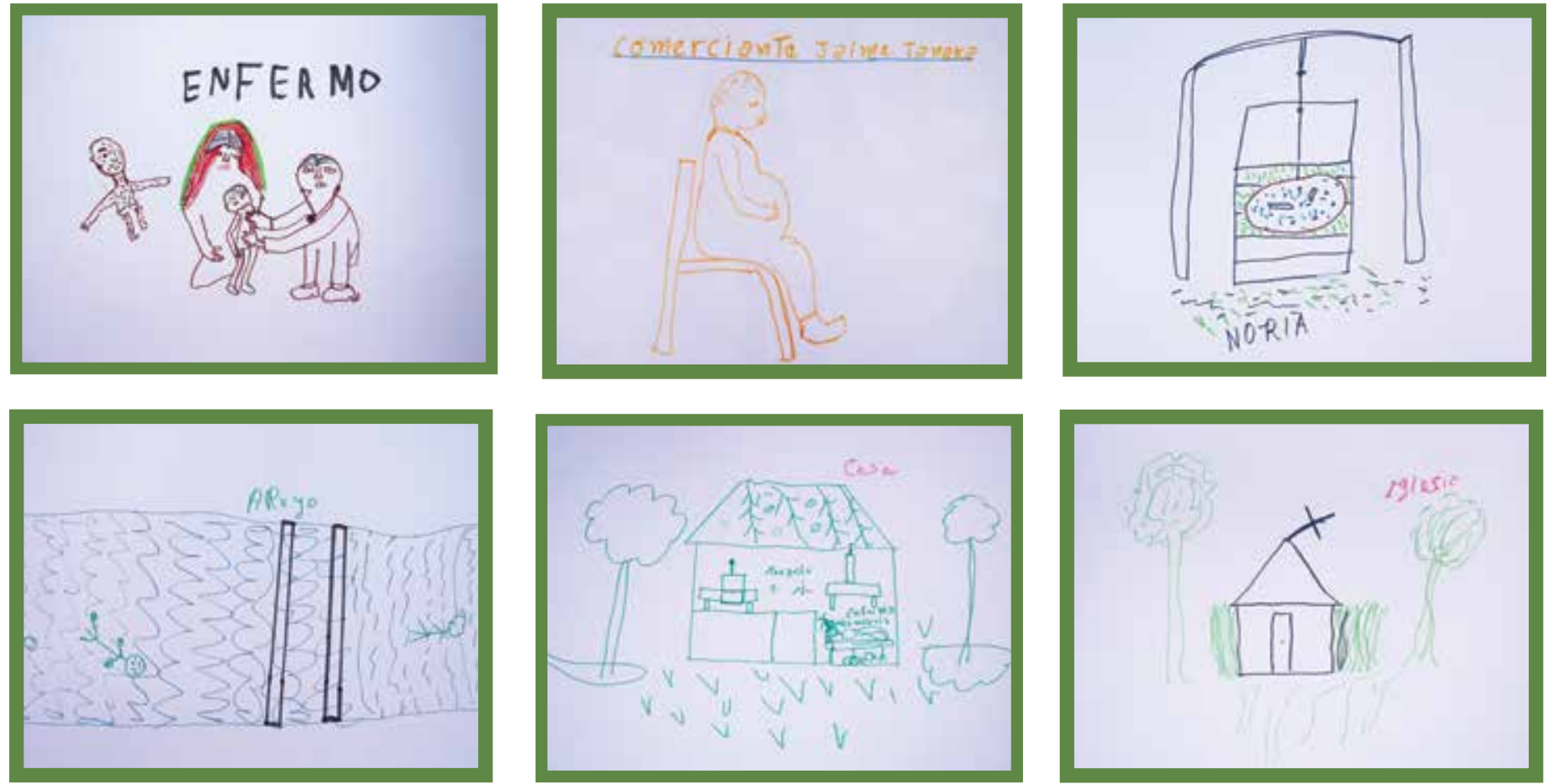

Example of the concerns expressed by women in the northern Bolivian Amazon during a Visioning exercise. Clockwise from upper left: illness, merchant who takes advantage of them, unfinished well, dilapidated church, dark house with insects and illness, dirty stream. 
We are going to take a walk 20 years into the future, so first we will have to make time speed up. As I count to 20, you are growing older. Your children have grown, the community has changed, has improved. Life is getting better, everyone is happier. Problems have been solved. When you open your eyes, you will be here, but 20 years in the future.

Elaborate as much as possible to try to pull the participants into an imaginary state. Have fun, but be careful! Do not attempt to tell them what they see in the future - that is their job.

Now lead the group in a walk around the community and the forest. Stop at specific points in and around the community, such as the stream, well, road, school, farms and houses, and ask them to describe what they "see" in the ideal future. Encourage the free flow of ideas, and try to make sure that everyone is participating. Make sure the note taker is recording the discussion.

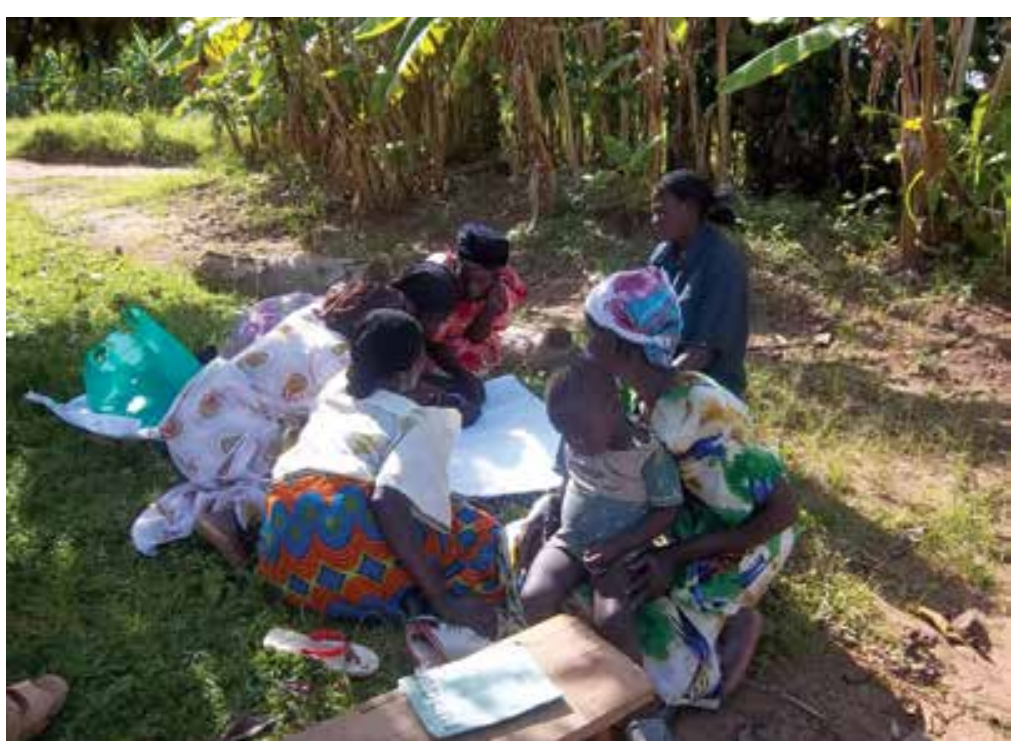

Photo by Concepta Mukasa

\section{Discussion questions:}

- What do you want to see here in 20 years?

- What are people doing?

- What are the families, the children, the trees and animals like?

- What does the land around the community look like?

- What are people doing for a living?

- How has the community changed: the houses, roads, water, school?

- What has not changed?

- You discussed problems earlier: how have those problems been solved?

\section{Option 2: Guided Vision}

This approach is ideal if the workshop is not taking place near the community. It can also free people from the constraints of their current situation because they are not physically walking through their community, unlike in the Walk in the Future. If effectively facilitated, this method can be very powerful (Wollenberg et al. 2000).

Ask participants to sit quietly, relax, close their eyes and clear their minds.

Imagine that you have left the community. After 20 years without contact, you return to find that things have turned out well. You are walking around and observing the community. Describe (silently in your mind) how you know things are better: What does the village look like? What are the houses like? What are people doing? Who do they see? What do you notice about the forest, land, streams and farms? What has changed? What has not changed?

After 15-20 minutes of imagining, the participants open their eyes and write down or draw the things that stood out most in their vision. Then, comparing these ideas, it becomes clear how similar or different everyone's expectations are. 
Step 3: Drawing tomorrow's vision (1 hour)

After the Walk in the Future or the Guided Vision, return to the workspace and ask the participants to form small groups and draw or write down their desired vision. Groups may wish to share a large poster-board so that everyone can participate at the same time, and those without reading skills can also contribute. Alternatively, groups might choose to write out a list of ideas. This step is best done with minimal facilitation; rather, allow the participants to organize themselves and decided how they will complete the task.

\section{Step 4: Presenting, discussing and prioritizing (1 hour)}

Bring the breakout groups back to the workspace. Tape all of the visions to the wall and have each group present its work. Then ask the entire group to discuss and compare the visions.

\section{Discussion questions:}

- What seems to be most important in each vision?

- What do the visions have in common?

- What is different between them?

- What is most surprising to you?

During this process, a note taker writes out a list of the ideas presented on a flipchart. After the group discussion, post the list of ideas on the wall to vote on them. Everyone receives several votes (these can be cut-out stars, squares or paper, or the voting can be done with a marker) and can place their votes next to one or more of the ideas that are the most important to them. Count up the stars and rank the ideas. Identify those ideas that got the most votes and prioritize. Decide which one should be the focus of the first ACM-related work. Be alert to differences by gender, age, ethnicity, etc. — for future reference, at least.

\subsubsection{The Problem Tree}

If the group has already identified a priority or problem, the Problem Tree can be used to further understand the causes and

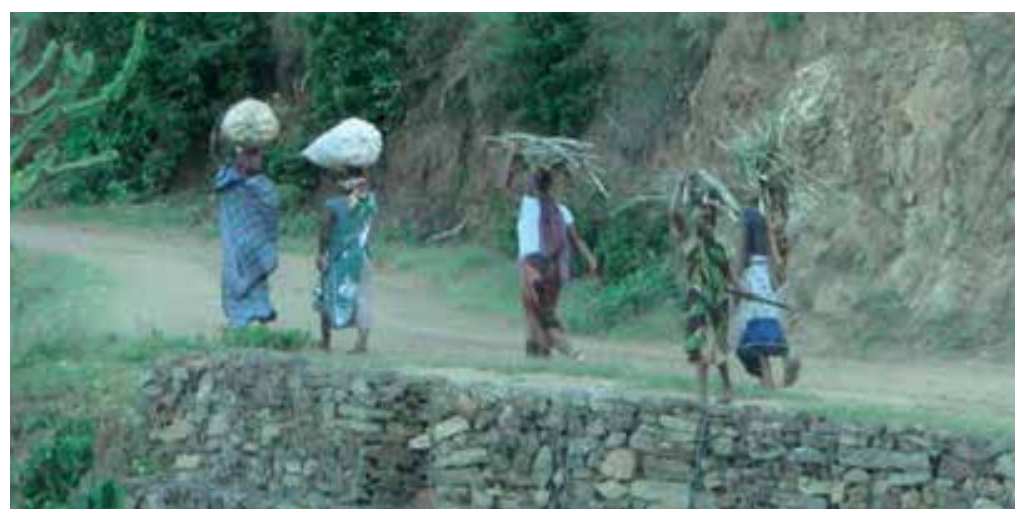

Photo by Esther Mwangi

impacts. This is especially important if the community is dealing with a complex issue that requires more exploration and thought.

\section{Objectives:}

- Identify the obstacles to solving the problem. This will form the basis for the action plan (in the next step).

- Clarify the cause-effect relationships characterizing the problem.

- Portray the complexity of the problem.

\section{Step 1: Preparation (30 minutes)}

- Divide the participants by gender and age (men, women, youths).

- Write the problem/priority identified in the previous step in the middle of a piece of flipchart paper.

- What are the roots of the problem? Draw them growing downward, like tree roots.

- What are the effects of the problem? Draw those branching upward, like tree branches.

\section{Step 2: Grow the tree by asking questions (1 hour)}

Below is a checklist of questions to consider, including but not limited to the following: 
- What is the problem?

- Why is it a problem?

- What really is the problem and why? (Return to questions you asked earlier to get everything right.)

- Is the problem a symptom of something else? (A problem within a problem?)

- What would happen if the problem is not solved?

Step 3: Group presentations of trees in the plenary session (1 hour)

- Help participants draw out similarities and differences between problems identified by different groups in order to come up with one tree for the whole community.

- Guide participants in reaching a consensus description of the solutions to the problems.

- An objective tree is then developed out of the problem tree by reformulating the negative statements into positive objectives.

- Each objective will then serve as the basis for the action plan (next step).

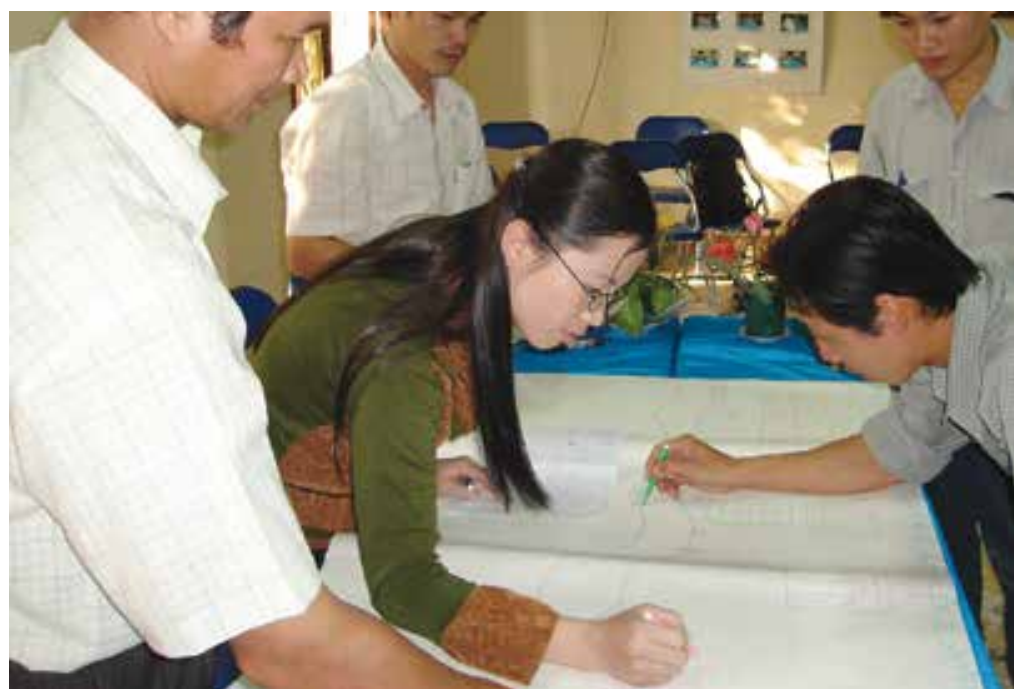

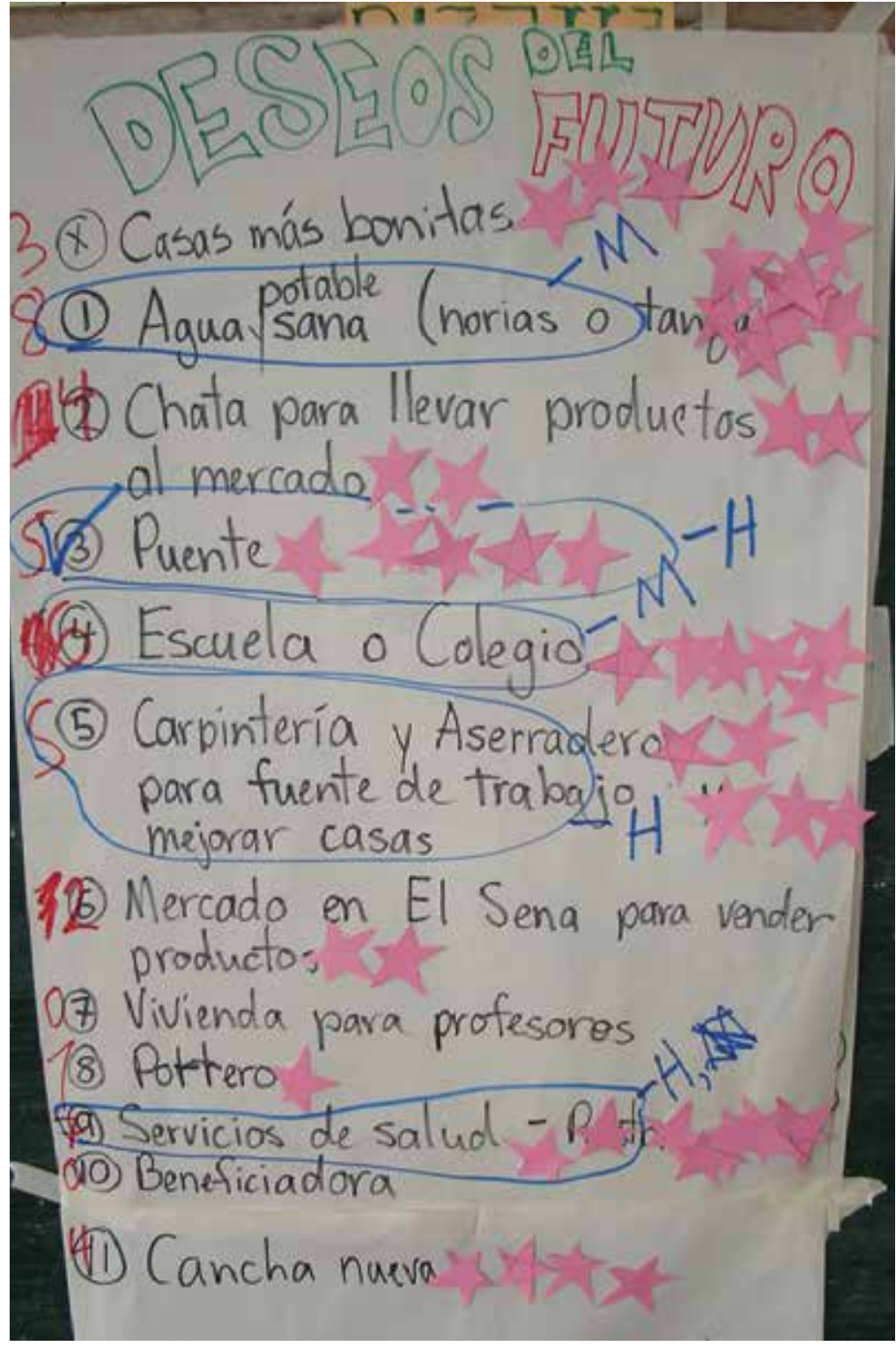

Participants prioritize aspects of their desired future from the Visioning exercise. 


\subsection{Make a plan}

After identifying a priority through the Visioning or Problem Tree exercises, participants identify how to turn that priority into a reality. They do this by developing specific plans and strategies, using a Pathways exercise. The Pathways exercise creates a bridge from the present to the future by comparing how things are today with the ideal future or desired goal.

\section{Step 1: Analyze present obstacles (1 hour)}

For each priority, have the participants explore the present situation. Ask them to identify what they have to change about the present in order to achieve their desired goal: How is the present reality different from the future goals? What are we lacking? What is keeping us from achieving our goal? If they did a Visioning exercise, they can compare their vision of the ideal future with their current situation to identify the differences between the two. If they did a Problem Tree, the root causes can be used here.

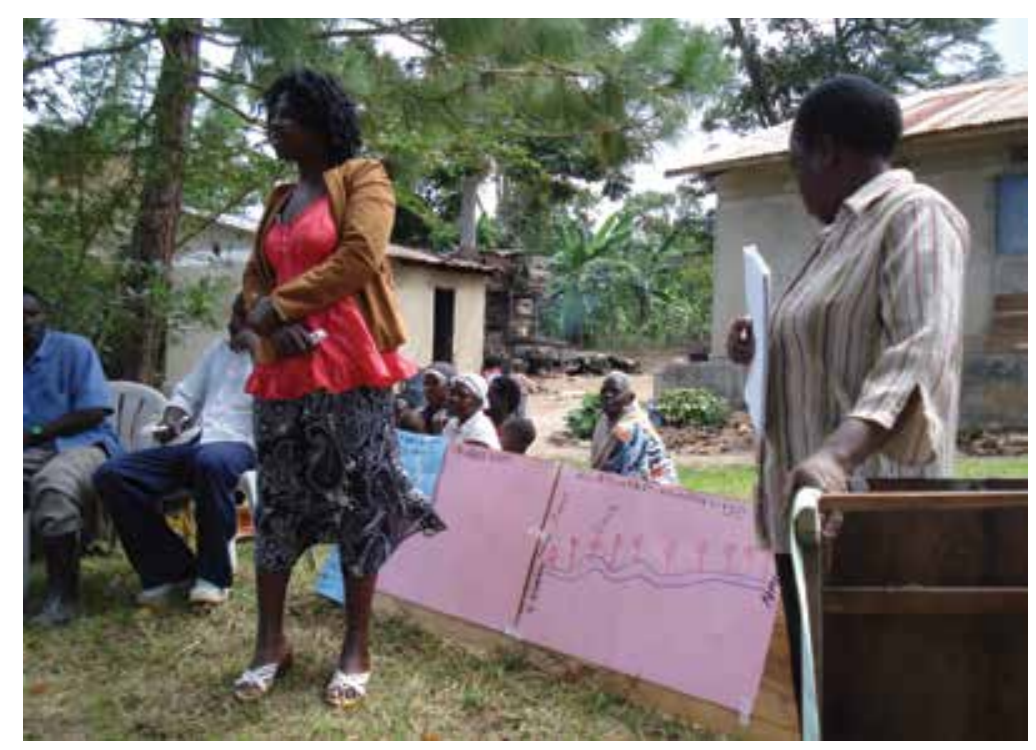

Next, have the participants analyze the advantages or resources they already have at their disposal in order to achieve their goal: Do we have talents or skills in the community that will help us? Do we have resources or rights that we can leverage? Are there existing partnerships with other communities or institutions or others that we can develop?

\section{Step 2: Develop strategies to reach the goals (1 hour)}

Next, for each obstacle or element missing, ask participants to create a strategy of "how, who, and when" to solve the problem. $\mathrm{Be}$ as detailed as possible about dates and responsibilities. If the strategy is specific, it is easier for the community to monitor the follow-through. See Figure 5 for an example.

Have the participants work in breakout groups, with each group assigned to produce one strategy. If this is the first time that the participants have engaged in any type of group planning, they may be surprised to find that they can quickly arrive at concrete solutions and decisions.

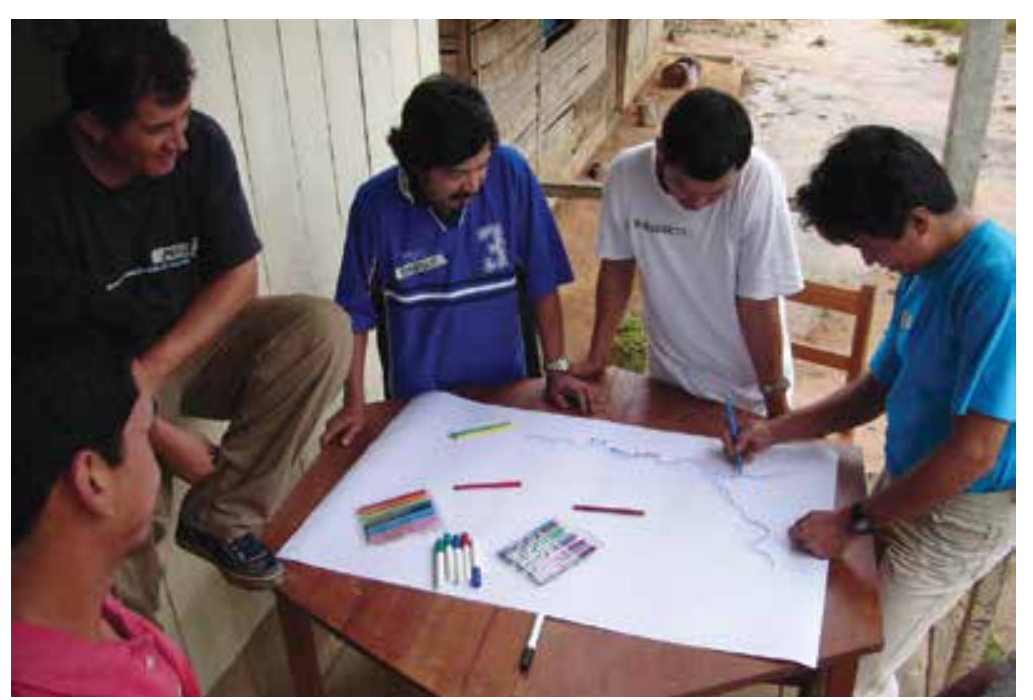




\section{Step 3: Group discussion (1 hour)}

Bring the breakout groups back together and have each present its strategy. Analyze and discuss together, allowing for adjustments. Suggest steps for monitoring progress on the strategies.

\section{Discussion questions:}

- Are these strategies reasonable?

- What will be the biggest obstacles or possible challenges to the strategies? How can we overcome them?

- What other people outside of the community will you have to include in this process?

- Who could we talk with who might be able to help?

- How will we ensure that the people assigned to a task complete it?
- When will we monitor the progress of these strategies? Who will be in charge of organizing the monitoring?

\section{Tips and options}

- First pick an example to demonstrate the steps to the entire group. Then divide the participants into breakout groups and assign one or two goals to each group to apply the Pathways steps.

- This exercise can be adapted to groups with more experience in planning and more technology available, but the concept remains the same: developing plans with detailed dates and responsibilities that can be monitored for follow through.

\begin{tabular}{|c|c|c|c|c|}
\hline $\begin{array}{l}\text { What advantages or resources do we have } \\
\text { that we can leverage? } \\
\text { - A partially finished water well } \\
\text { - Manual labor } \\
\text { - Skilled craftsmen } \\
\text { - Wood }\end{array}$ & & Strategy & & \multirow[t]{7}{*}{$\begin{array}{l}\text {...Future goal } \\
\text { accomplished!! } \\
\text { A water well that is } \\
\text { finished, clean and } \\
\text { always full of water }\end{array}$} \\
\hline \multirow{6}{*}{$\begin{array}{l}\text { What are we lacking and what obstacles } \\
\text { do we have to overcome in order to reach } \\
\text { our goal? } \\
\text { - A water well that is full of sticks, toads and } \\
\text { mud that dries up in the dry season } \\
\text { - Well lining } \\
\text { - Platform } \\
\text { - Well cover } \\
\text { - Materials: iron bars, bricks, bucket, rope, } \\
\text { cement, pulley, sand } \\
\text { - Transportation for the materials } \\
\text { - Dig the well deeper, clean it } \\
\text { - Money: total of about } 2500 \mathrm{Bs,} \mathrm{which} \mathrm{equals} \\
\text { a box and a half of Brazil nuts per family } \\
\text { - } 1375 \text { Bs for materials } \\
\text { - } 1000 \text { Bs to rent a truck from the city for } \\
\text { the materials } \\
\text { - } 100 \mathrm{Bs} \text { to rent a truck from a neighboring } \\
\text { village for the sand }\end{array}$} & How will we change that? & Who will do it? & $\begin{array}{l}\text { When will it } \\
\text { be done? }\end{array}$ & \\
\hline & $\begin{array}{l}\text { First demand that the mayor } \\
\text { help finish the well. }\end{array}$ & $\begin{array}{l}\text { A commission from the } \\
\text { community, composed of } \\
x, y \text { and } z \text {. }\end{array}$ & April & \\
\hline & $\begin{array}{l}\text { Collect a box and a half of } \\
\text { Brazil nuts from each family. }\end{array}$ & $\begin{array}{l}\text { Claudia, the community } \\
\text { treasurer }\end{array}$ & March & \\
\hline & Buy the materials. & $\begin{array}{l}\text { The treasurer Claudia, } \\
\text { the craftsman Guido and } \\
\text { community leaders }\end{array}$ & $\begin{array}{l}\text { The first days of } \\
\text { April }\end{array}$ & \\
\hline & Buy cement. & Claudia and Guido & September & \\
\hline & Build and clean the well. & $\begin{array}{l}\text { Workers and all of the } \\
\text { community }\end{array}$ & September & \\
\hline
\end{tabular}

Figure 3. Example of a pathways plan developed in Amazonian Bolivia to finish an incomplete water well project in the community.

26 Field guide to Adaptive Collaborative Management and improving women's participation 


\section{Monitor and reflect}

\subsection{Monitor and reflect}

Before, during and after their activities, the participants should be collecting information to track whether they are making progress toward their goal — in other words, monitoring. Monitoring is the primary way that we learn in ACM. By monitoring together, community members discover the impacts of their actions, and keep moving ahead toward their long-term goals. Monitoring activities provide a space for sharing knowledge and reflecting on the results. Every monitoring activity should be followed by a discussion about what the results mean.

ACM facilitators should work with community members to develop the monitoring plans at the same time as the activity plan. That helps link the plans to monitoring.

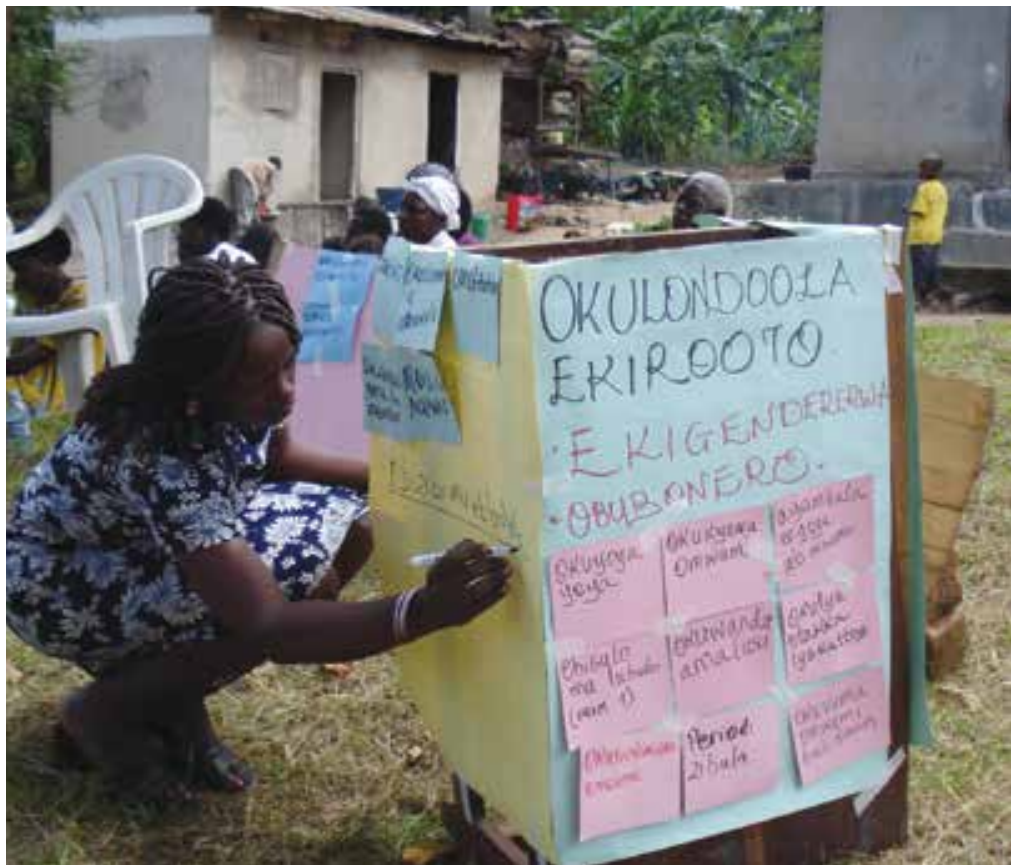

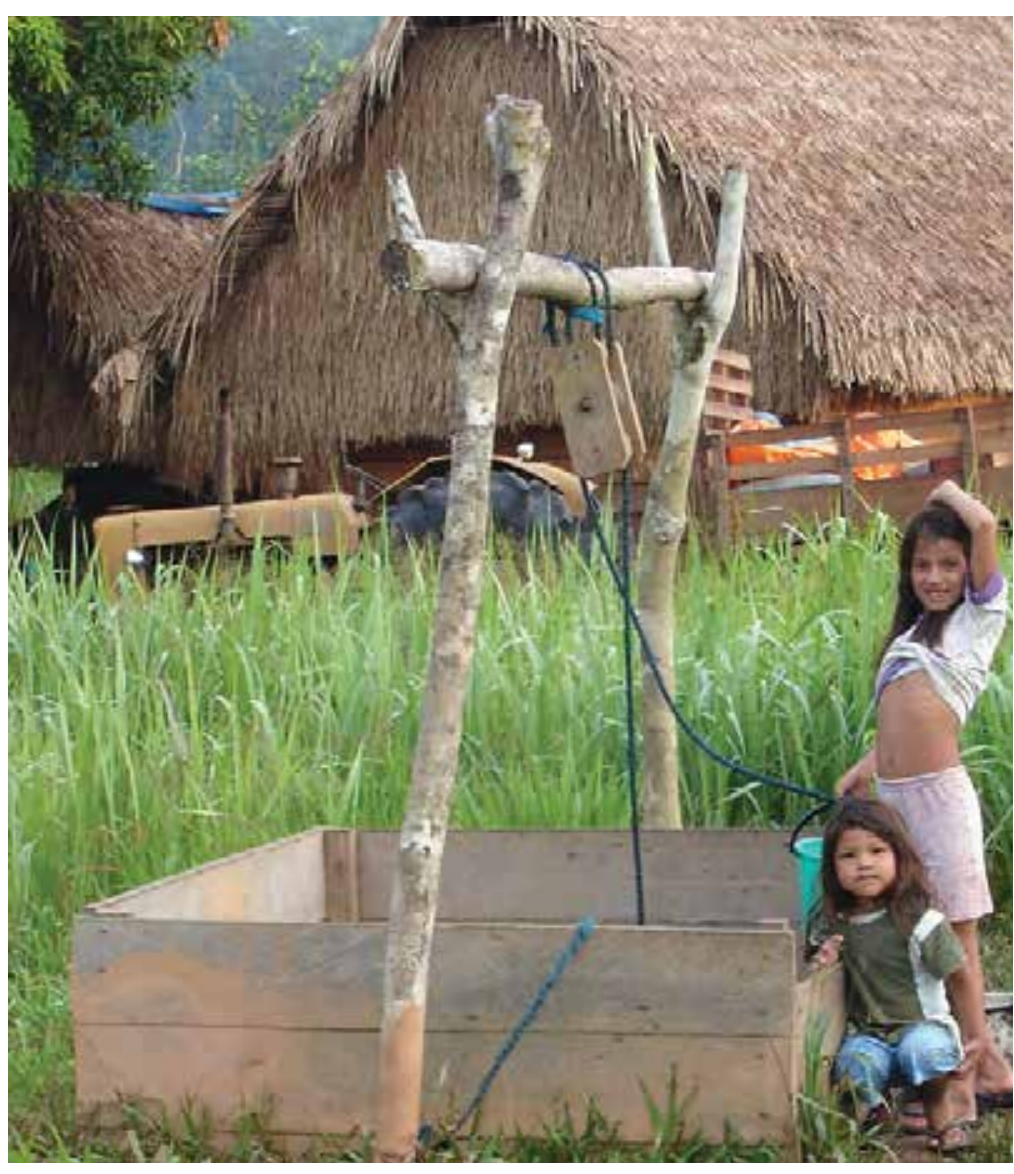

If the participants are new to monitoring or planning, keep it simple - monitoring is about observing what is happening, writing that down and reflecting on it together. Depending on the location and culture, it may be simpler to avoid using the term "indicator" at first. You might find that participants best learn monitoring by doing monitoring. On the other hand, participants may already have a good grasp of monitoring — adapt your discussion to their knowledge level. However, keep in mind that even if a few people know what monitoring is, many other 
community members, particularly those who have been excluded in the past (e.g., women), may be new to the concepts and you do not want to leave them out.

Following is a workshop to explain what monitoring is and how to devise a monitoring plan. Even if participants are familiar with monitoring, it can be helpful to review the concepts to make sure everyone is on the same page.

\section{Objectives:}

- Understand what monitoring is

- Understand the importance of monitoring in ACM

- Devise a simple monitoring plan

Following are the steps.

\section{Step 1: Introduce the basic concepts}

What is monitoring? Monitoring is the collection and analysis of information to track change. Monitoring can take many forms. For example, a community might monitor the progress of a reforestation project by measuring the health of the newly planted seedlings every three months. Counting the number of times women speak in each community meeting is a way of monitoring whether women's participation is improving or not.

\section{Box 7. How do you say "monitoring" in...}

The term "monitoring" can sound technical and confusing. Search for the best way to describe monitoring in simple, practical words. Use terms that are recognized at the local level. For example, monitoring in the indigenous language Miskitu can be described as "Pura kaikaia", translated as "looking from above". Monitoring in Mayangna is"Minit talnin", which can be translated as"accompanying or supervising". Be careful: In Indonesian, one word for monitoring, "pengawasan", translates literally as "control", which is not the right meaning for ACM (Kusumanto et al. 2005).

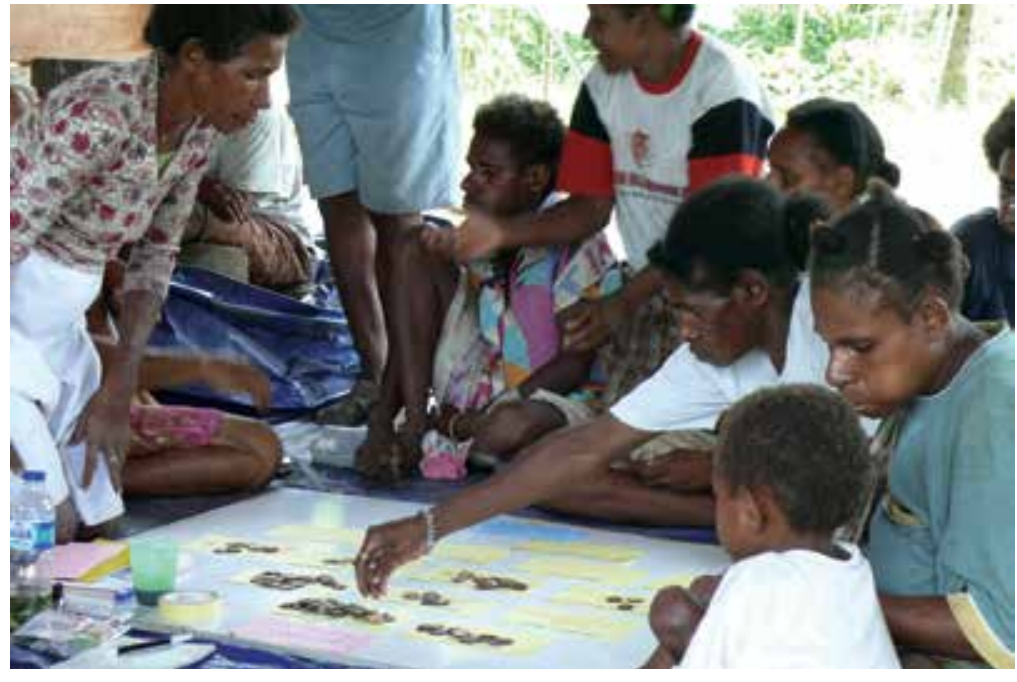

Photo by Michael Padmanaba

\section{Why monitor?}

- To learn more about a situation or process

- To respond to concerns or questions

- To enforce compliance with rules or regulations

- To demonstrate progress to outsiders (e.g., donors).

Monitoring provides the information needed to analyze things based on specific observations, instead of guesses or assumptions. Monitoring must have a purpose: one does not monitor simply to monitor. And you cannot monitor everything. It is not uncommon for a project to try to monitor many things without a clear idea why, and people quickly abandon the activity. Monitoring should respond to this question: "Is the action we are taking having the effect that we expected?"

\section{Importance of note taking}

Monitoring requires writing things down. It isn't enough to simply go and look. Also, monitoring requires multiple observations. It is often done by several people so it is important that they observe 

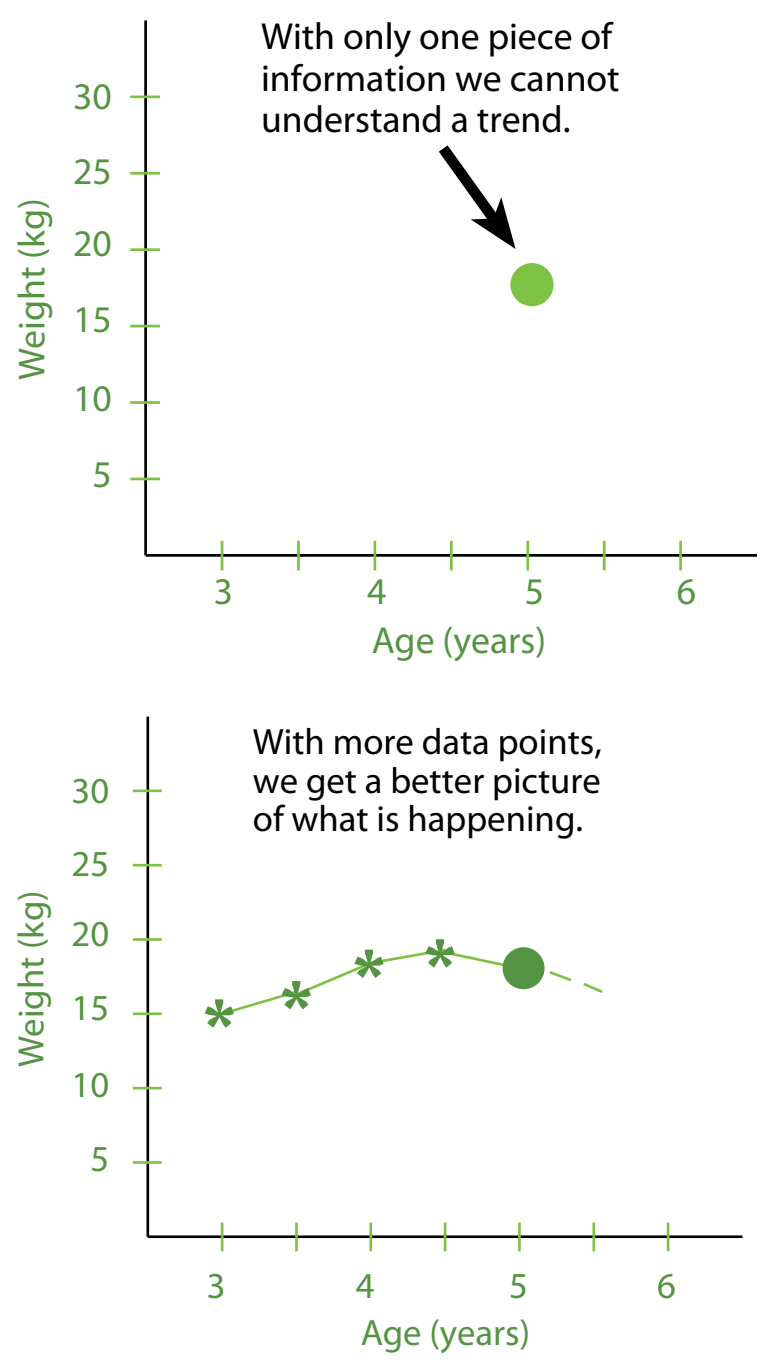

Figure 4. What is monitoring? Monitoring is the systematic collection of data to understand if and how something is changing. When information is collected at only one time point (for example, the weight of a child), we cannot see a trend (top). With information collected more than once, we have a better picture of what is happening (below). Borrowed from CIFOR (2007).

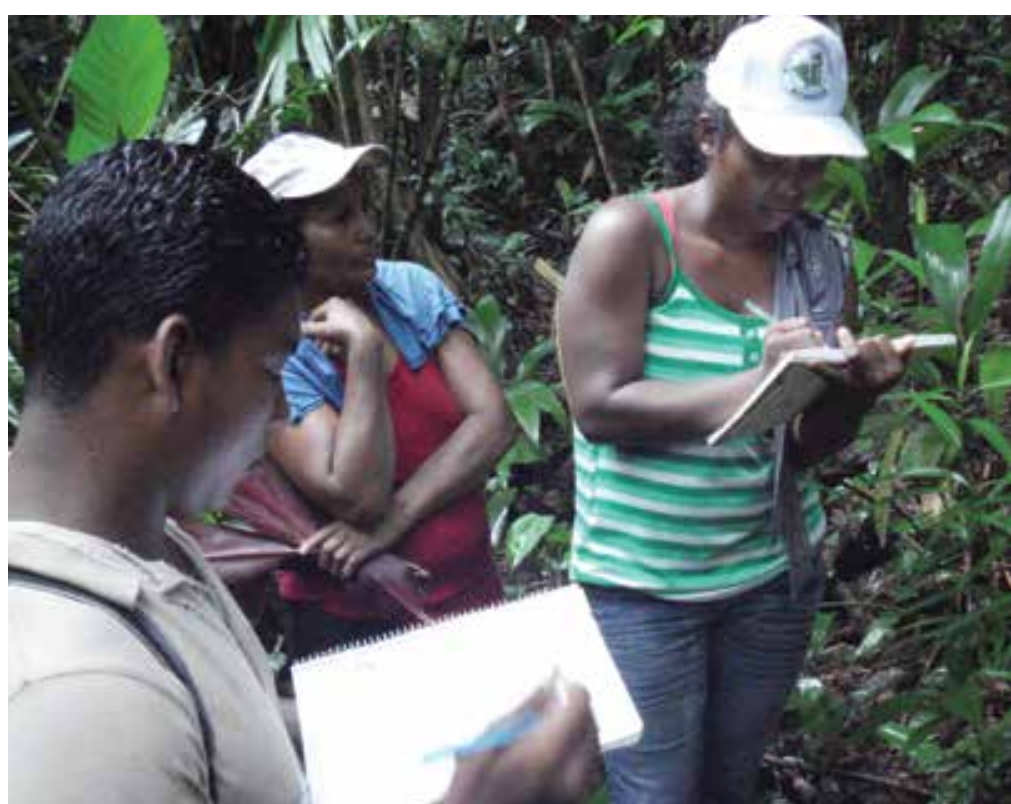

Community members monitor the tree seedlings in a reforestation project in Nicaragua. They are recording height, number of leaves, amount of sunlight and spacing between trees. The woman with good writing skills is recording the information. Her companion who does not write, but who can read numbers, is taking the measurements.

Monitoring is not just about collecting data. Monitoring is a conversation.

the same things, at the same intervals, and, if they are measuring the observations, using the same methods. It would be hard to remember all that information or have any way to compare it unless the observations are documented. Information must be recorded on paper so that it is available for review and comparison the next time that monitoring happens. 
Box 8. Monitoring the books in Bolivia, and learning along the way

In the community of Cururu in Bolivia, there were concerns about how a community forestry project was being managed. In particular, people did not know how much money was being spent on wages. The ACM team worked with the community's bookkeeper to set up a wage-monitoring system where everyone could review the payments made to community members and their receipts. Periodically the notebooks were presented for review. People double-checked the calculations and identified any errors. Community members learned about wage distribution, bookkeeping and transparency. They also gained trust in their bookkeeper and leaders (Cronkleton et al. 2006).

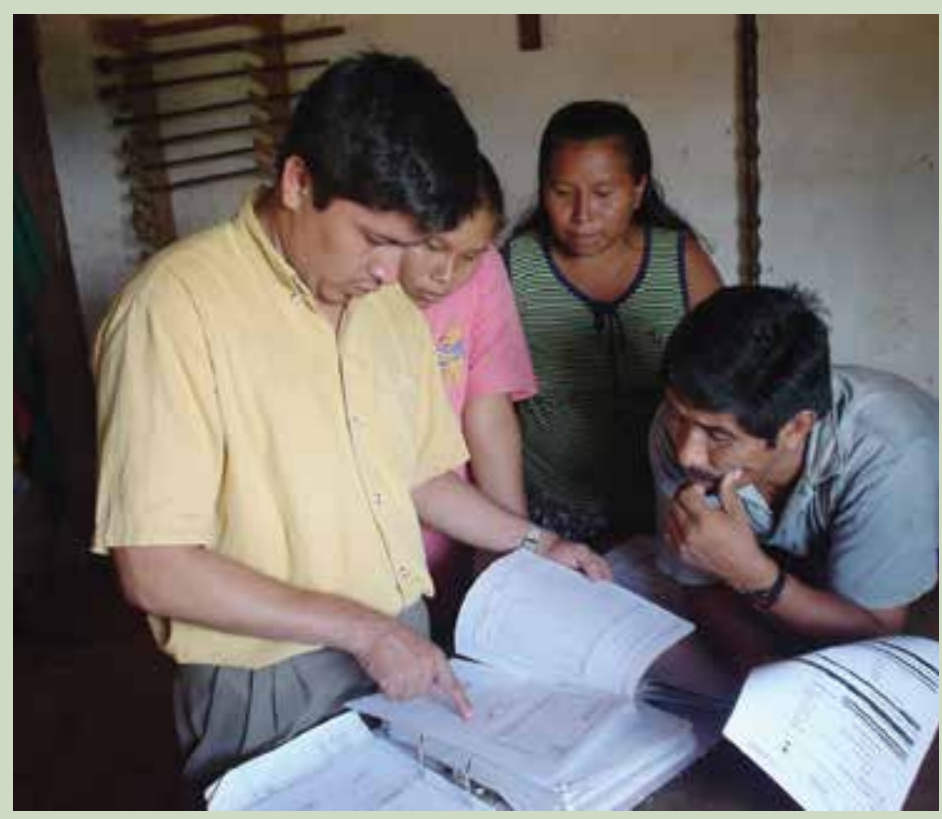

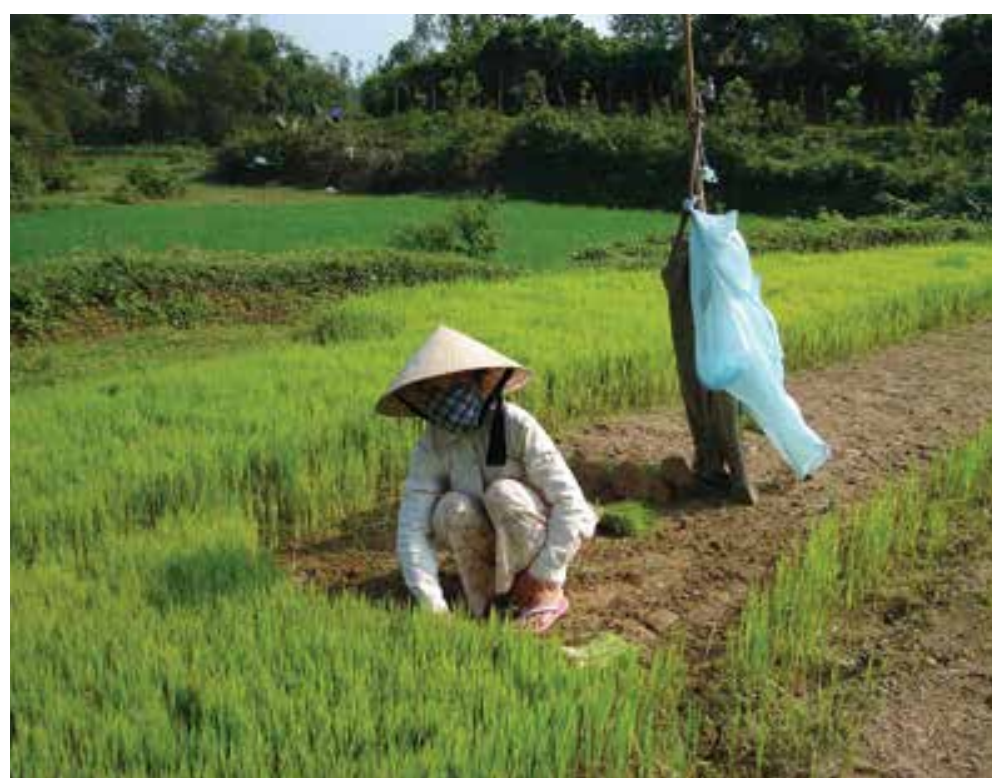

Here are two common examples of monitoring that might help explain the concept:

- Monitoring pregnancy: An expectant mother visits a clinic regularly and her weight is monitored. At every visit, the nurse writes down the information. Over time it will be possible to compare these observations to see if she is gaining weight, losing it or staying the same. If she is not gaining enough weight, the nurse might tell her to eat different things, drink more water or take certain vitamins. And then the nurse will tell her to return to see if it worked.

- Monitoring crops: A successful farmer doesn't just plant seeds and wait till harvest. She visits the field every week. She notes how much of the seed has germinated, whether it is growing as expected and whether it is time to clear the field of competing weeds. If the plants are weak, she waters them or adds fertilizer. She might change what she plants the next season based on what she learned. 


\section{How often do we monitor?}

- More than once. It could be every day, week, month or year. The interval for making observations should be tied to the cycles of the "worm" (see Figure 1). The interval depends on what is being monitored and how frequently the participants expect to be able to see change.

- Systematically. If not, the risk is that people just monitor when there is a problem, but then it is difficult to tell if the problem being observed is a rare occurrence or part of an overall trend.

- Depends on the activity and on the resources available.

Facilitators should encourage groups that are new at initiating ACM activities to focus on phenomena with short cycles.

That way people can learn the entire process and understand why each step is taken without losing interest.

\section{What is an indicator?}

An indicator is an observation of what we expect to see changing. It allows us to understand a more complex situation. For example, a common saying is "where there's smoke, there's fire". Smoke is an indicator of fire. So there are sometimes towers for people to monitor the forest for fires. As another example, the weight of a child can be an indicator of health (see Figure 4). Weight is not exactly the same thing as health, but if we monitor a child's weight, that information gives us a sense of whether the child is healthy and growing properly.

A good indicator is measurable and easy to collect. An indicator may be a fact, such as the diameter of a tree, or it can be a perspective on a situation, such as whether it is improving.
The following Table 1 has some examples of indicators.

\section{Table 1. Examples of indicators}

\begin{tabular}{|c|c|c|}
\hline To monitor.... & $\begin{array}{l}\text { Good indicators may } \\
\text { be.... }\end{array}$ & How often? \\
\hline $\begin{array}{l}\text { Trees planted for } \\
\text { a reforestation } \\
\text { project }\end{array}$ & $\begin{array}{l}\text { Number of trees, height of } \\
\text { the seedlings, number of } \\
\text { leaves, general health, type of } \\
\text { soil, amount of shade }\end{array}$ & $\begin{array}{l}\text { Every } 3 \text { months } \\
\text { initially, then every } \\
12 \text { months as the } \\
\text { trees mature }\end{array}$ \\
\hline $\begin{array}{l}\text { Participation of } \\
\text { women in meetings }\end{array}$ & $\begin{array}{l}\text { Percentage of women and } \\
\text { men who attend meetings, } \\
\text { percentage of women } \\
\text { who speak at meetings, } \\
\text { percentage of decisions } \\
\text { based on proposals made by } \\
\text { women }\end{array}$ & $\begin{array}{l}\text { Every community } \\
\text { meeting at first; } \\
\text { at longer intervals } \\
\text { later }\end{array}$ \\
\hline $\begin{array}{l}\text { Community } \\
\text { benefits of a } \\
\text { forestry project }\end{array}$ & $\begin{array}{l}\text { Income generated, } \\
\text { distributions to community } \\
\text { members, expenses, } \\
\text { participation in meetings, } \\
\text { appreciation of things } \\
\text { learned, group cohesion } \\
\text { (Cronkleton et al. 2006) }\end{array}$ & $\begin{array}{l}\text { Quarterly } \\
\text { presentations of } \\
\text { accounts }\end{array}$ \\
\hline $\begin{array}{l}\text { Sustainable honey } \\
\text { production }\end{array}$ & $\begin{array}{l}\text { Sources of water, important } \\
\text { flowering trees and trees that } \\
\text { provide ideal conditions for } \\
\text { placing hives, reduction in } \\
\text { thefts (Kamoto 2007) }\end{array}$ & Monthly \\
\hline Building a well & $\begin{array}{l}\text { Whether materials were } \\
\text { purchased, whether money } \\
\text { was collected, how much } \\
\text { work has been done on the } \\
\text { well (Evans et al. 2006) }\end{array}$ & $\begin{array}{l}\text { At monthly } \\
\text { community } \\
\text { meetings }\end{array}$ \\
\hline
\end{tabular}

There are many ways to create monitoring activities that are participatory and that do not require technical expertise. See Participatory Monitoring in Tropical Forest Management (Evans and Guariguata 2008) for more ideas. 


\section{Box 9. ACM can start with a simple question}

An ACM program in Indonesia explored linking monitoring to learning and advancing forest governance in Jambi, Sumatra. The participatory monitoring program focused on three local governance mechanisms: the election committee, community meetings and information dissemination throughout the community. Monitoring began with simple questions, such as "How do we ensure that people vote in the correct districts?" As the process evolved, the questions became more politically valueladen and complex. The authors learned that as stakeholders' capacities evolve, the monitoring program needs to adapt to answer their new questions. The process helped to institutionalize a culture of accountability and transparency that did not exist before; for instance, when an oil palm plantation company wanted to use community land, the refusal was based on majority sentiment, not a decision by local elites (Kusumanto 2007).

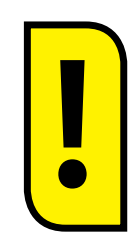

Indicator danger!

It can be easy for community members - and facilitators! - to get confused by indicators and bogged down in long discussions trying to decide which indicators to monitor. The term itself may sound strange and technical. Our Nicaragua team found it best not to use the term at all, and instead simply asked "What should we monitor?"

For example, a research project in Nepal initially set out to develop an indicator set with local community forest user groups. Several problems soon became apparent: it was difficult to convey the meaning of "monitoring" and "indicators" and difficult to develop consensus about the meaning of specific indicators. The entire process got bogged down in the process of identifying indicators. They changed the approach: they identified priority issues and developed a plan to resolve and monitor those issues. By shifting the focus away from indicators, monitoring ceased to be a separate activity and became part of a larger process that concentrated on the discussion of issues, reflection and action (Paudel and Ojha 2007).

Keep in mind that indicator danger might not be a problem where you are working. ACM teams in Indonesia, Philippines, Zimbabwe, Malawi and Cameroon have found no problems with defining indicators (Colfer 2005a, 2005b).

\section{Step 2: Design a monitoring plan}

Divide the participants into groups of 4-6 people each and ask each group to create a basic monitoring plan for an aspect of their action plan. Tell each to:

- Reflect on the "worm" with regard to the action plan. What do you expect (or want) to change? For example, one community in Nicaragua was concerned about the amount of timber being sold from community forests, and their action plan relied on community leaders addressing the problem. They decided to monitor the amount of wood being moved out of the community. To do that, they needed a workshop on timber volume calculations, which both women and men participated in.

- Fill in the following Table 2:

Table 2. Creating a basic monitoring plan

\begin{tabular}{|l|l|l|l|l|}
\hline $\begin{array}{l}\text { What do we want to } \\
\text { monitor? }\end{array}$ & $\begin{array}{l}\text { What activity will we do to monitor? } \\
\text { (measure something, talk to people, present } \\
\text { at a meeting) }\end{array}$ & $\begin{array}{l}\text { When (how often) } \\
\text { do we monitor or } \\
\text { measure? }\end{array}$ & $\begin{array}{l}\text { Who does the } \\
\text { monitoring? }\end{array}$ & $\begin{array}{l}\text { When and how often should } \\
\text { monitoring results be shared } \\
\text { among stakeholders? }\end{array}$ \\
\hline & & & & \\
\hline
\end{tabular}




\section{Monitor and reflect}

Remember: Keep the monitoring simple and relevant

Monitoring plans do not have to follow a format like the table above. Useful monitoring can be started by asking simple questions. For example: "What would you like to observe or measure? What things might change with time?"

Instead of developing the monitoring plans in a meeting, go straight to the site of what you need to monitor. For example, in Nicaragua, instead of holding a workshop on monitoring in the village school, the ACM facilitator took participants out to the trees that had been planted and asked what the participants wanted to know about the trees to make sure they were healthy. They decided as a group to measure height, number of leaves on a seedling, condition of the soil, amount of light and general observations of the trees' health. The facilitator never used the word "indicator".

\section{Monitoring gender}

In some cases, there may be little recognition that women are not participating as much as men because people have not "noticed". Monitoring can provide a non-confrontational way to raise awareness and introduce discussions of gender equity.

\section{Example: Gender monitoring during meetings}

By collecting simple data on participation during meetings and activities and then presenting the data at the close of the event, participants have an immediate opportunity to analyze and reflect on the results.

See Section 4.3 for a gender participation monitoring worksheet developed by an ACM team in Nicaragua.

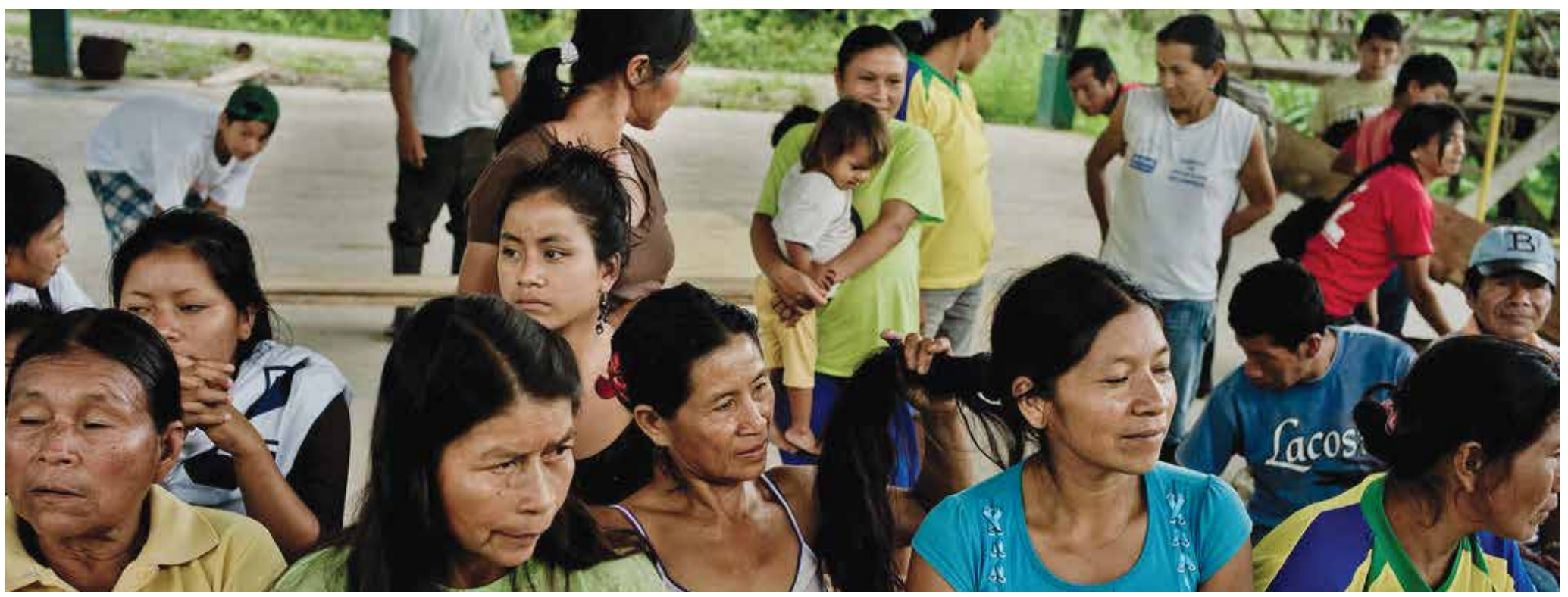

Photo by Tomas Munita 


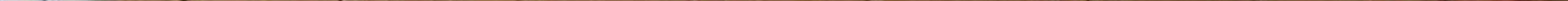




\section{Take action}

\subsection{Take action}

Now the community has an action plan with specific activities to do. These activities could be anything, such as planting trees, creating resource use rules, learning to process fruit, controlling fire, cutting lianas, developing a childcare center, creating a cooperative to sell forest products and many other possibilities.

While this step may seem simple, it actually requires significant support from the ACM team. Most work will consist of accompanying the community members in the field-based activities (e.g., mapping, forest diagnostics, tree planting, seedling monitoring) and village-based activities (e.g., attending assemblies, meetings, monitoring participation, training). With

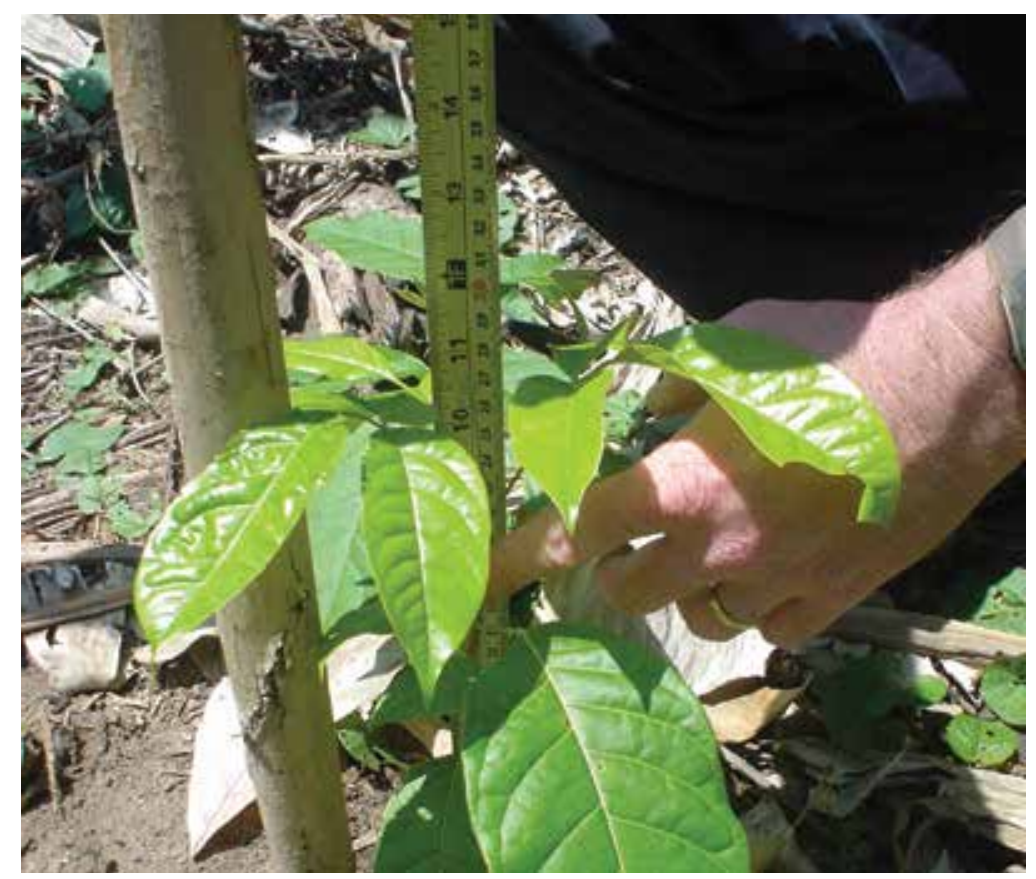

the workshops completed, the role of the ACM team shifts from facilitator to guide. The team will now be guiding and advising the community members as they implement their action plans and monitoring activities.

This will demand that your ACM team now assume the roles of ACM mentors and advisors, with the knowledge that good advisors know when to ask for help and when to relinquish control. Your emphasis will shift to:

1. creative problem solving and guidance by the field team as they accompany the community in their projects as they move forward

2. a confident understanding of how to identify opportunities for learning, which are core to ACM, in order to facilitate reflection on the activities and monitoring as they occur

3. proactive management skills to keep the projects on track outside the structure of workshops

4. continuing to promote participation and evolving local leadership

5. assisting with developing capacities for local communities/ women to act and helping to identify resources.

\section{Box 10. Monitoring gender yields surprising results}

At a rural village in Uganda, the ACM team monitored participation of men and women in a meeting. The group had expected to find that men dominated the meeting. However, the results surprised them. Of the 60 people who attended, only nine people participated. Among those nine, participation was split relatively equally between men and women. The monitoring activity dispelled misperceptions about participation and gave new insights into where work was needed to improve participation. 
Remember that the central goal of ACM is to learn by doing together. This means that you should be encouraging and facilitating the work (not doing it), as well as facilitating platforms for various stakeholders to reflect and learn.
As the projects move into a phase where the focus is on doing the activities and monitoring them, the community co-facilitator can be encouraged to take a more active role as "community project manager". It may be important to return to the issue of whether the co-facilitator should be paid, and by whom. The community can also pay its own members if they choose.

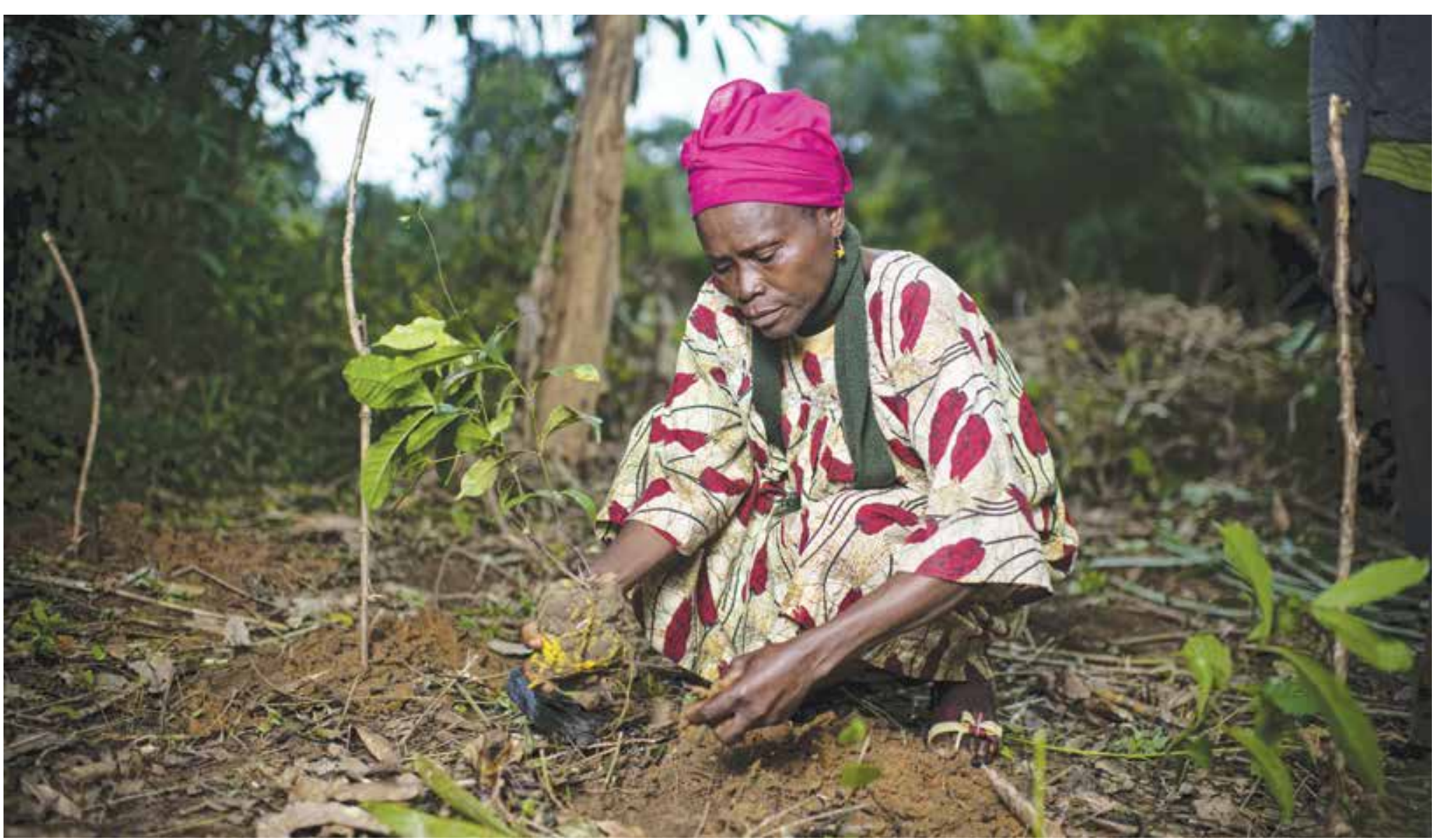

Photo by Ollivier Girard

36 | Field guide to Adaptive Collaborative Management and improving women's participation 


\subsection{Reflect and take new action}

After one or two monitoring activities, organize a community meeting to present and reflect on the results. The participants should help present the information.

\section{Questions to discuss are:}

- What do these results mean?

- What can we learn from them?

- Are things going as we planned?

- How can we improve?

Based on the discussion, make adjustments to the plans and activities as needed.

Continue the cycle of monitoring-reflection-new action until the project goal is reached. This may take 1 month, 1 year, 2 years or 10 years. In some cases, such as the long-term management of a forest, this process will continue indefinitely.

\subsection{Improving women's participation}

There are many different types of barriers to women's participation in decision making and forest activities. Some of these barriers can be addressed in the way that you organize and facilitate the activities.

\subsubsection{Giving women voice in meetings}

Direct questions to women about their opinions and interests can help elicit their comments. Examples:

- "What do you think of this, Sara?"

- "What do the women think of this?"

- "What could the women be doing in this activity?"

\section{Box 11. Priming the pump}

Often ACM requires resources to launch the activities. CIFOR committed US\$1800 to help finance activities contained in the ACM action plans developed by three communities in Nicaragua. Village 1's goal was reforestation of its water catchment area. Its plan included a forest diagnostic of the watershed, a reforestation plan and an information campaign to discourage deforestation. Village 2's goal was reforestation, involving leadership development, analysis of deforested area, development of internal rules for forest management and a reforestation plan. Village 3's goal was stronger natural resource management. Its plan included leadership development and development of internal rules.

The community "investment" funds committed by CIFOR were relatively modest, but they had an out-sized impact:

1. The funds demonstrated an institutional commitment to the communities without creating the dependency and counterproductive behaviors (locally called "projectitis") that often come with large sums of money.

2. The resources primed the pump to launch the projects by providing key - but still modest - resources at the outset.

3. The transparent, participatory and collaborative manner in which the plans were presented and approved set a positive example for the communities.

4. They instigated an institutional counterpart commitment by INAFOR, the Nicaraguan Forestry Service, to provide 10,000 seedlings for the project.

Create other opportunities for participation for those who do not like to speak in group settings:

- Make decisions by physically marking an opinion or choice (not just raising a hand). Everyone gets a vote! 
- Instead of brainstorming in a group, have each participant write down her ideas on cards that are then shared with the group. Caution: This could be a barrier to women who cannot read/write (see below).

In workshops, women may be more likely to participate in small groups, either women-only or mixed gender:

- Women-only breakout groups help create an environment where women are comfortable speaking.

- On the other hand, putting women in groups with men (usually best if there is a critical mass of women in the group) gives women an opportunity to show men that they know what they are talking about. In one community where the women were struggling to get involved, once men and women broke out into small groups, women took on important roles: actively participating in discussion, writing on the flipchart paper and presenting the group's work in front of the larger group.

\subsubsection{Giving women confidence}

In many areas, a big barrier to women's participation is a lack of confidence. This can be reinforced by men's perceptions and expectations. Here are some suggestions for addressing those issues:

- Create an environment of trust.

- Make a special effort to learn women's names.

- Speak with them personally.

- Make informal visits to households to encourage their participation.

- Set agreed-upon rules for group engagement, such as agreeing that members will not "put each other down" or dismiss others' input. That can be brought out with a "hopes and fears" discussion at the beginning of the process (repeated from time to time).

- Give pep talks about value of getting diverse perspectives, the waste of human resources by ignoring half the population, the insights that women may have

\section{Box 12. Challenges of managing a new project}

In a fishing village in Ghana, the women wanted to build a market to sell their fish and improve their incomes. The village chief was behind the proposal, but they still had to overcome a series of barriers. For instance, local leaders wanted to fill in wetlands, which were fish-spawning areas, instead of the proposed site. The meeting to resolve the situation was planned for a time that was during the market day, meaning that women had to sacrifice income to attend. Finally, the local assembly man who held the site plans delayed providing them to the district planner for over five months.

Once the site was decided upon (a high-ground area that did not require filling in wetlands) and work started, it became clear that there were many more issues to plan, including the following:

- Who will manage the running of the market? What incentives should be put in place for the market managers?

- What are the market rates and how they will be used by the community?

- Who will get market stands and what are the criteria for selection?

As is often the case, it is not the technical aspects of management that are complicated, but rather the collaboration between people and their different interests. Keep in mind that ACM is an iterative process revisiting plans and adjusting them in a systematic and collaborative way is what it is all about!

Common challenges and solutions:

- Resistance from key stakeholders who may not support ideas being implemented $\rightarrow$ More discussions and negotiations to come to a joint understanding of what is being done and why.

- Stakeholders not doing their part (e.g., the district people who took a long time to provide the site plan) $\rightarrow$ Be patient but also follow up with stakeholders who promised to do something.

- Further planning may be required (e.g., plans for using the market) $\rightarrow$ Identify what planning must be done, gather the stakeholders and do it.

(Personal communication from T Mutimukuru-Maravanyika, 2013) 


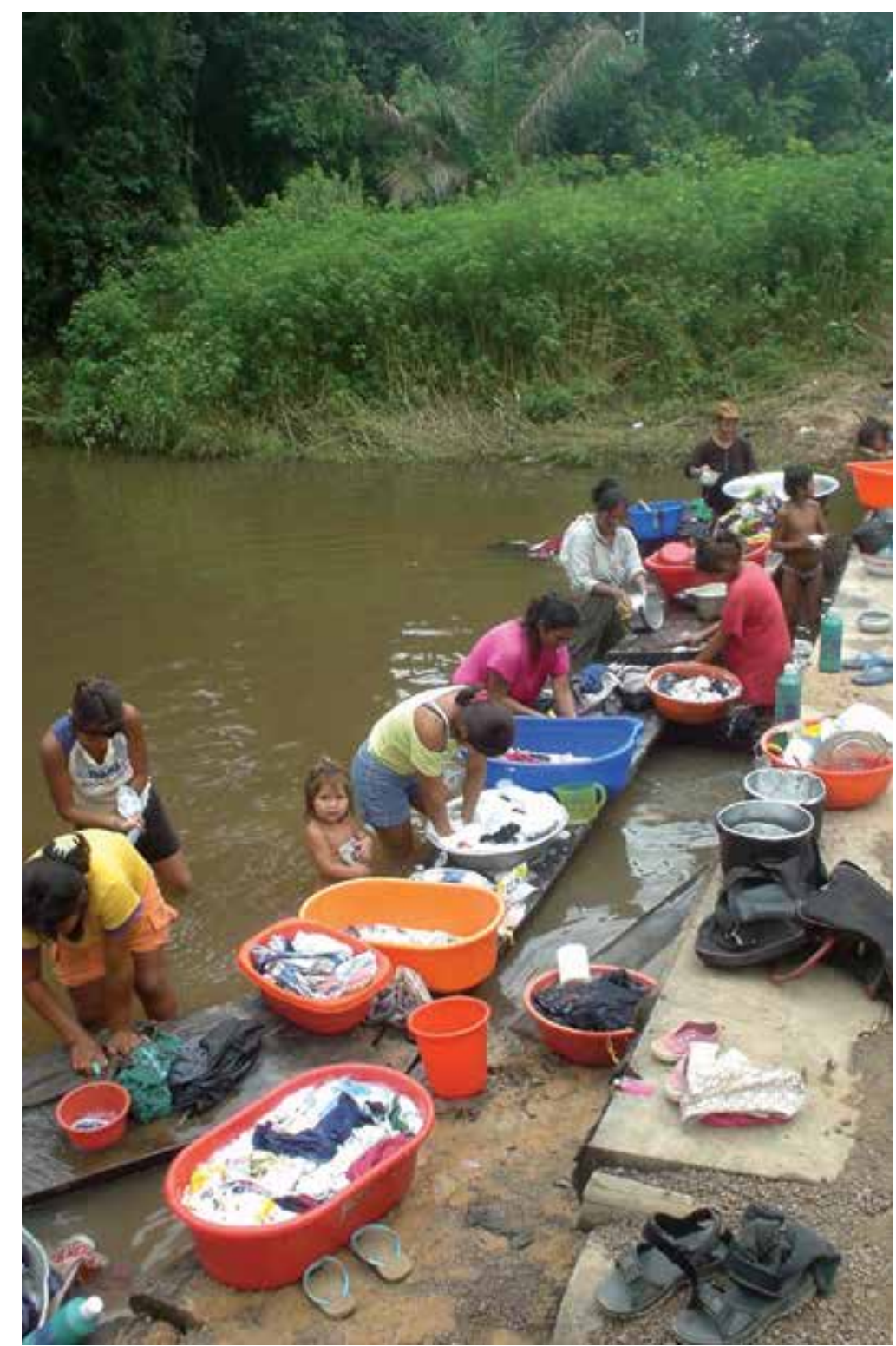

The community clothes washing spot is often where women share ideas and chat. This can be a great place to discuss ACM.

\section{Box 13. Gender issues in Nicaragua}

In Nicaragua, the ACM team changed their own perspectives about gender as they worked with communities and ACM.

"Gender issues" had been commonly misperceived as a zerosum game - taking power from men to give it to women - or as a domestic abuse issue. Through ACM, the team realized that the issue was much broader, including norms and values about men's and women's behavior, power dynamics and interactions between men and women. We realized that it focused on one relationship among many, and that at core, it was about collaboration (Manfre and Rubin 2013).

people to address issues, but they can also lead to serious divisions and may require special attention and conflict resolution efforts.

In the Mafungautsi State Forest of Zimbabwe, there had been a long history of conflict between the local forestry commission (FC) and communities. The ACM team observed a significant lack of trust between the FC and communities. The situations had also created a strong sense of disempowerment among the communities. The team had to come up with ways to build trust. They organized a Training for Transformation (T-for-T) workshop. First developed in Kenya in 1974, T-for-T is based on Paulo Freire's Pedagogy of the Oppressed (Freire 2001). It strengthened people's confidence through extensive use of visualization techniques, games, stories, short plays and mottos such as "nobody knows everything and nobody knows nothing". Following the T-for-T workshop, the ACM team introduced professional conflict resolution experts to help the communities and FC recognize the existing conflict, identify available alternatives and come up with jointly agreed solutions (Mutimukuru-Maravanyika and Matose 2013). 


\section{Additional resources}

\subsection{Facilitation skills}

(adapted from Evans et al. 2006)

Paraphrasing. Paraphrasing helps participants follow the discussion and assists the note taker in accurately recording the important points. Use your own words to reflect what an individual speaker is saying and how that speaker is feeling by saying the following:

"If I understood well, what you mean is..."

"I think what you are saying is..."

Questioning. Ask questions to explore a comment or issue. Open-ended questions usually begin with "what", "how", "when" "where" and are posed in such a way so that speaker has to elaborate with more detail. Clarifying questions draw out the speaker's point and often begin with "which", "why", "do you mean to say", etc. Closed questions can be answered with a "yes" or "no" and are asked to get specific information.

Encouraging participation. Use facial expressions, body language and comments to encourage the speaker to say more about the situation. Some examples:

- nodding your head or saying "Uh-huh", repeating a sentence or part of a sentence, or saying "that's interesting, does anyone have something to add?"

- mirror the feelings: "It seems to me that this is a happy thing for you..."

- listen to and respect all of the participants' opinions.
The facilitator should never assume a "know-it-all" position or inject her opinion. When walking and talking with participants, bring stragglers into the group and ask them to share their opinions.

Maintaining high energy levels. Capture the attention of the participants and keep their energy levels high by doing short sessions, changing facilitators or facilitation styles, changing the furniture setup and using different dynamics of interaction. Always have a few energizers ready to use when the energy level lags; these could include physical exercises such as stretches, brief musical interludes or games.

\begin{abstract}
One trick is to use the "talking stick" when someone is clearly dominating - the person given the stick is the only one who can talk at that point. Another trick is to use "yellow cards" like in soccer/football: if someone is not following the group's agreed upon rules, anyone can hold up a card.
\end{abstract}

Summarizing. Identify and verbalize key elements or details of the conversation. The purpose of summarizing is to pull together important ideas, facts or data, establish a basis for further discussion, make a transition, review progress and check for clarity or agreement. Identify and verbalize key elements or details of the conversation. When summarizing, avoid aligning yourself with particular viewpoints: a facilitator should remain neutral (except 


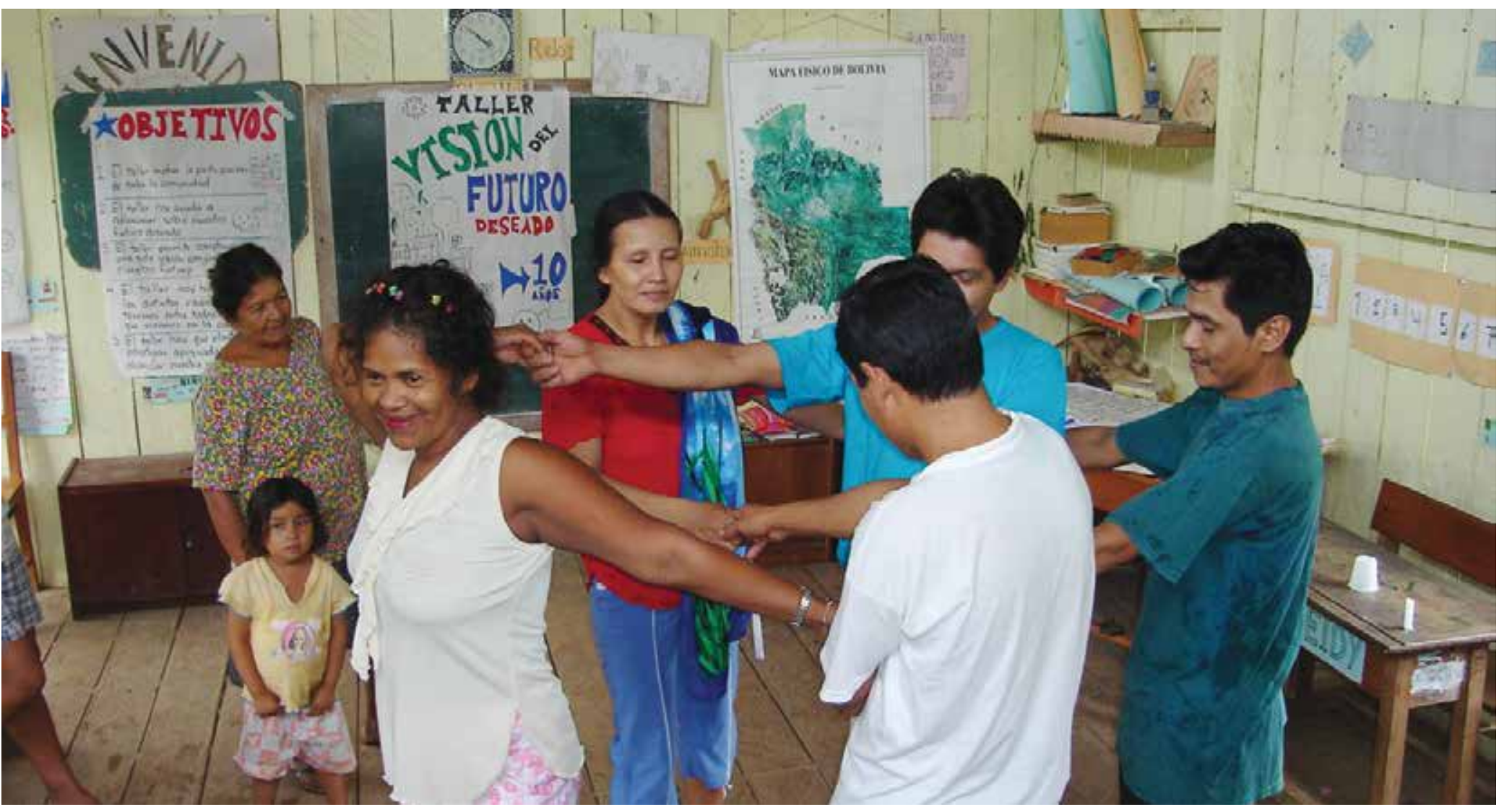

The Human knot is a fun and physical team building exercise.

in situations where one opinion is unfairly dominating). You could start by saying: "There seem to be some key ideas expressed here...", "Let's see what we have covered so far ...", etc.

Dealing with difficult participants. Difficult participants or "disrupters" can upset the flow of discussion by being rigid, rude or silent or not being serious. They may interrupt, dominate or fidget. Take any of the following actions depending on the disrupter:
- Ignore politely.

- Interrupt politely, but clearly.

- Stop the discussion.

- Talk it out publicly or personally to find out what is behind the behavior.

- Acknowledge and postpone.

- Form breakout groups (dominant participants can be more easily controlled in small groups and have less influence).

- Divert attention by starting a new activity. 
- Engage the disrupter in controlled debate.

- Ask others for help.

If the behavior persists and threatens a successful meeting (this is very rare!), the participant should be invited to leave.

Moving along. Avoid taking up too much time discussing the same subject or being repetitive. On the other hand, be aware that having too little discussion might prematurely assume consensus when in reality not all opinions have been heard. Determining when a group has talked about something just enough — not too much, not too little - is not an exact science but is a very important facilitation skill.

Getting to closure. Summarize the discussion to help the group move toward agreement. When agreement is difficult, the discussion should be facilitated openly and positively. Work to summarize major points of disagreement and alternatives without dominating. Creative ideas and mutual understanding often emerge out of disagreement.

Capitalizing on diversity. When working with a diverse group, take time to discuss the roles that all participants play and the value of different opinions. Participants with different religious affiliations, races, ages, jobs, education or economic level contribute distinct perceptions and experiences. Disagreements are inevitable and are a good sign of worthwhile discussion. An experienced facilitator can channel diversity into a constructive, positive outcome. Organize people into small groups to encourage participation by less vocal participants. Consider separating men and women, neighborhoods or generations for some activities, and then have the groups share. If unsure about cultural sensitivities, consider asking the community how the groups should be divided.

\subsection{More facilitation tips}

- Post a "roadmap" of the activities on the wall to keep the exercise on track. This can be a picture drawn on a flipchart of the activities or a written agenda. Refer to it frequently.

- When brainstorming, emphasize that participants should feel free to express any ideas. Approach every contribution with respect and interest, gently probing to generate subsequent ideas. Set out the ground rules, for example, a) start no evaluation or discussion until all ideas are recorded, b) everybody participates.

- When situations get emotional or heated, help the participants analyze their ideas objectively by categorizing them:

- Fact: a commonly agreed upon truth that is verifiable

- Opinion: a personal or group view on a topic

- Rumor: unsubstantiated information

- Feeling: I don't want something to happen / I fear...

- Use an energizer to defuse heated situations.

- Use examples as much as possible when explaining concepts.

- Use the breaks to evaluate the development of the exercise. Ask participants' opinions about specific activities.

- Try to incorporate drawing into the activities to encourage participation by people who do not read or write.

\subsection{Gender monitoring worksheet}

The following worksheet is a basic device for monitoring the participation of people in a meeting by gender. Ask at least two participants to complete this sheet during every meeting. At the close of each meeting, the results should be presented for discussion by the entire group. 
Date of the activity/meeting:

Name of the activity/meeting:

Goal of the activity/meeting:

Who called the activity/meeting:

\begin{tabular}{|c|c|c|}
\hline & & \\
\hline
\end{tabular}

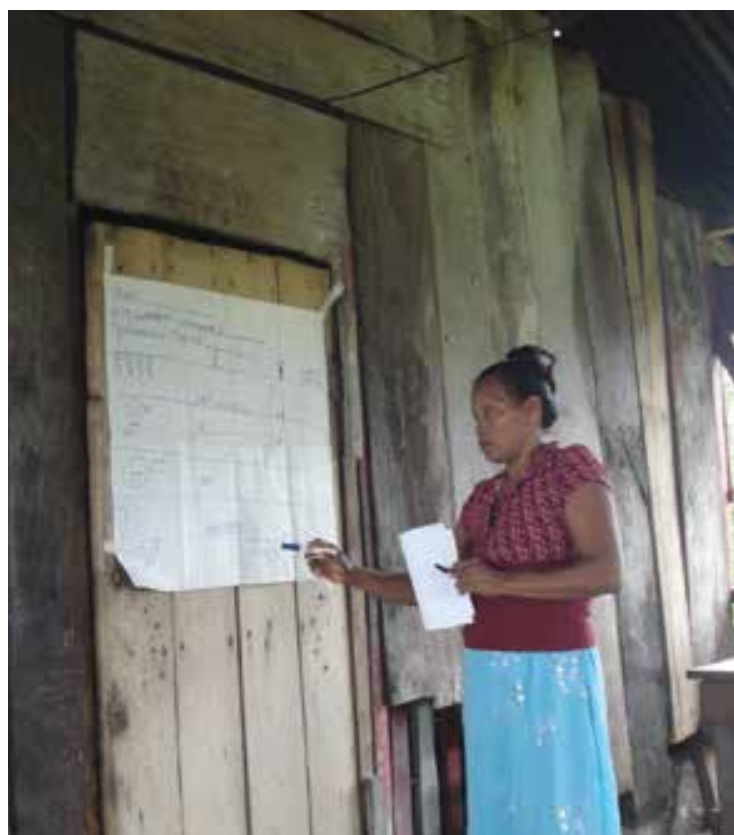

Figure 5. Community member shares her results of monitoring participation of women and men. 


\section{References}

\subsection{Publications}

Borda, OF, and Rahman, MA. 1991. Action and Knowledge: Breaking the Monopoly with Participatory Action-Research. New York: Apex Press.

[CIFOR] Center for International Forestry Research. 2007. Towards Wellbeing in Forest Communities: A Source Book for Local Government. Bogor, Indonesia: CIFOR. http://www.cifor.org/ publications/pdf_files/Books/BAlbornoz0701.pdf

Colfer CJP. 2013a. The ups and downs of institutional learning: Reflections on the emergence and conduct of Adaptive Collaborative Management at the Center for International Forestry Research. In Ojha HR, Hall A, Sulaiman V R, eds. Adaptive Collaborative Approaches in Natural Resource Governance: Rethinking Participation, Learning and Adaptation, 48-102. London: Routledge.

Colfer CJP. 2013b. The Gender Box: A Framework for Analysing Gender Roles in Forest Management. CIFOR Occasional Paper No. 82. Bogor, Indonesia: CIFOR. http://www.cifor.org/publications/ pdf_files/OccPapers/OP-82.pdf

Colfer CJP. 2007. Simple Rules for Catalyzing Collective Action in Natural Resource Management Contexts. Bogor, Indonesia: CIFOR. http://www.cifor.org/publications/pdf_files/Books/ BColfer0701.pdf

Colfer CJP. 2005a. The Complex Forest: Communities, Uncertainty, and Adaptive Collaborative Management. Washington, DC: Resources for the Future/CIFOR.

Colfer CJP. 2005b. The Equitable Forest: Diversity, Community and Resource Management. Washington, DC: Resources for the Future/CIFOR.
Colfer CJP, Andriamampandry E, Asaha S, Lyimo E, Marini E, Pfund JL and Watts J. 2011. Participatory action research for catalyzing adaptive management: Analysis of a "fits and starts" process. Journal of Environmental Science and Engineering 5:2843.

Colfer CJP, Prabhu R, Gunter M, McDougall C, Miyasaka Porro N and Porro R. 1999. Who Counts Most? Assessing Human WellBeing in Sustainable Forest Management. Bogor, Indonesia: CIFOR. http://www.cifor.org/acm/download/toolbox8.zip

Cooke B and Kothari U. 2001. Participation: The New Tyranny? London: Zed Books.

Cronkleton P, Keating R and Evans K. 2006. Helping village stakeholders monitor forest benefits in Bolivia. In Guijt I, ed. Negotiated Learning: Collaborative Monitoring in Forest Resource Management, 58-65. Washington, DC: Resources for the Future.

Dangol S. 2005. Participation and decision-making in Nepal. In Colfer CJP, ed. The Equitable Forest: Diversity, Community and Resource Management, 54-71. Washington, DC: Resources for the Future/CIFOR.

Evans K and Guariguata MR. 2008. Participatory Monitoring in Tropical Forest Management: A Review of Tools, Concepts and Lessons Learned. Bogor, Indonesia: CIFOR. http://www.cifor. org/publications/pdf_files/Books/BGuariguata0801.pdf

Evans K, Velarde SJ, Prieto RP, Rao SN, Sertzen S, Davila K, Cronkleton P and de Jong W. 2006. Field Guide to the Future: Four Ways for Communities to Think Ahead. Nairobi: CIFOR, ASB, World Agroforestry Centre. http://www.asb.cgiar.org/ PDFwebdocs/Evans-et-al-2006-Field-guide-to-the-future.pdf 
Freire P. 2001. Pedagogy of the Oppressed. New York: Continuum.

German L, Tiani AM, Daoudi A, Mutimukuru-Maravanyika T, Chuma E, Jum C, Nemarundwe N, Ontita E and Yitamben G. 2012. The Application of Participatory Action Research to Climate Change Adaptation in Africa: A Reference Guide. Ottawa: International Development Research Centre (IDRC). http:/www.cifor.org/online-library/browse/view-publication/ publication/4036.htm

Hartanto H, Lorenzo MC, Valmores C, Arda-minas L, Burton L and Frio A. 2003. Learning Together: Responding to Change and Complexity to Improve Community Forests in the Philippines. Bogor, Indonesia: CIFOR.

Kamoto J. 2007. Improving forest beekeeping through monitoring in Chimaliro, Malawi. In Guijt I, ed. Negotiated Learning: Collaborative Monitoring in Forest Resource Management, 10513. Washington, DC: Resources for the Future.

Kusumanto T. 2007. Learning to monitor political processes for fairness in Jambi, Indonesia. In Guijt I, ed. Negotiated Learning: Collaborative Monitoring in Forest Resource Management, 12436. Washington, DC: Resources for the Future.

Kusumanto T, Yuliani L, Macoun P, Indriatmoko Y and Adnan H. 2005. Learning to Adapt: Managing Forests Together in Indonesia. Bogor, Indonesia: CIFOR. http://www.cifor.org/publications/ pdf_files/books/BKusumanto0501.pdf

Lee K. 1993. Compass and Gyroscope. Washington, DC: Island Press. Manfre C and Rubin D. 2013. Integrating Gender into Forestry Research: A Guide for CIFOR Scientists and Programme Administrators. Bogor, Indonesia: CIFOR. http://www.cifor. org/publications/pdf_files/Books/BCIFOR1203.pdf

McDougall C, Pandit BH, Banjade MR, Paudel KP, Ojha H, Maharjan M, Rana S, Bhattarai T and Dangol S. 2009. Facilitating Forests of Learning: Enabling an Adaptive Collaborative Approach in Community Forest User Groups: A Guidebook. Bogor, Indonesia: CIFOR. http://www.cifor.org/publications/pdf_files/Books/ BMcDougall0901.pdf
Mutimukuru-Maravanyika T and Matose F. 2013. Learning in contested landscapes: Applying adaptive collaborative management in forested landscapes in Zimbabwe. In Ojha HR, Hall A, Sulaiman V R, eds. Adaptive Collaborative Approaches in Natural Resource Governance: Rethinking Participation, 177215. London: Earthscan.

Nyirenda R and Kozanayi W. 2007. Tracking broom grass resources for equity in Zimbabwe. In Guijt I, ed. Negotiated Learning: Collaborative Monitoring in Forest Resource Management, 66-72. Washington, DC: Resources for the Future.

Paudel KP and Ojha H. 2007. Imposing indicators or co-creating meanings in Nepal. In Guijt I, ed. Negotiated Learning: Collaborative Monitoring in Forest Resource Management, 49-57. Washington, DC: Resources for the Future.

Sithole B. 2002. Where the Power Lies: Multiple Stakeholder Politics over Natural Resources: A Participatory Methods Guide. Bogor, Indonesia: CIFOR. http://www.cifor.org/publications/pdf_ files/Books/where.pdf

Wollenberg E, Edmunds D and Buck L. 2000. Anticipating Change: Scenarios as a Tool for Adaptive Forest Management. Bogor, Indonesia: CIFOR. http://www.cifor.org/publications/pdf_ files/Books/scenarios.pdf

Wollenberg E, López C and Anderson J. 2005. Though All Things Differ: Pluralism as a Basis for Cooperation in Forests. Bogor, Indonesia: CIFOR. http://www.cifor.org/publications/pdf_ files/Books/BWollenberg0501.pdf

\subsection{Websites}

Center for International Forestry Research ACM project: http:// www.cifor.org/acm/

Collaborative Adaptive Management Network (CAMNet): http:// www.adaptivemanagement.net 



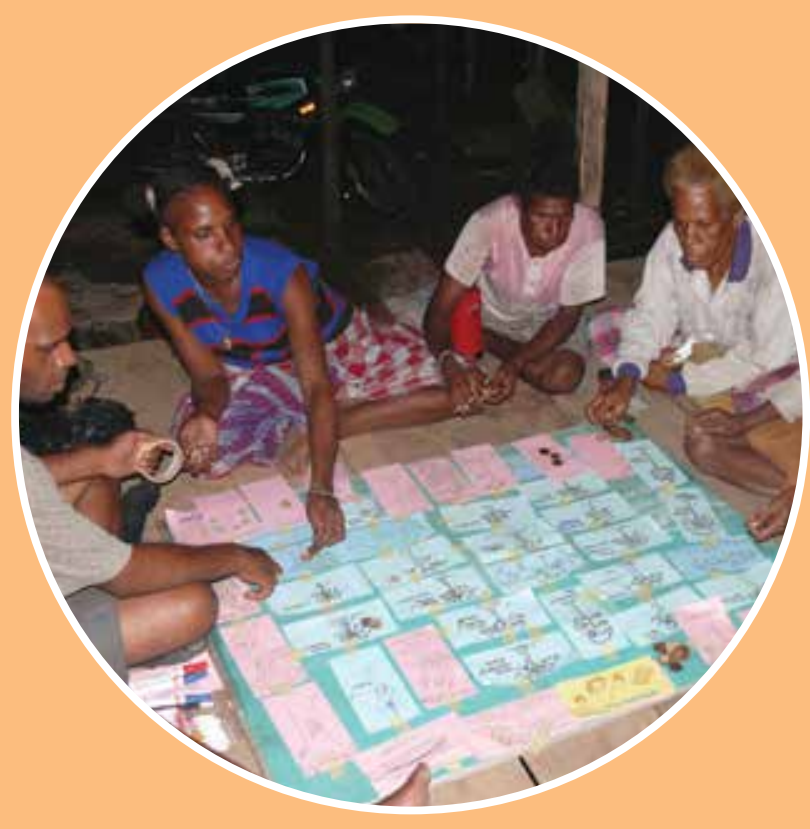

- Adaptive Collaborative Management (ACM) is a transformative problem-solving and management approach to learn and act collectively to systematically adapt to change and improve management outcomes.

- Women are crucial actors in forest management, yet their involvement in decision making has not kept pace with reforms in broader political and economic systems.

- This manual specifically addresses how to encourage the broader participation of women in decision making through ACM.

- We include practical guidance and examples of how to apply ACM methods in communities and how to teach those methods to others.

- We present an overview of ACM concepts, suggested steps and activities, tips, case studies and recommendations of additional resources.

- The ideas and activities that we present here come from field practitioners and community members who are managing forests, or who want to manage them better.

- This manual can also be applied to the management of a wide range of natural resources, such as natural forests, planted forests, crops, gardens, water or animals.

RESEARCH PROGRAM ON

Forests, Trees and Agroforestry
This research was carried out by CIFOR as part of the CGIAR Research Program on Forests, Trees and Agroforestry (CRP-FTA). This collaborative program aims to enhance the management and use of forests, agroforestry and tree genetic resources across the landscape from forests to farms. CIFOR leads CRP-FTA in partnership with Bioversity International, CATIE, CIRAD, the International Center for Tropical Agriculture and the World Agroforestry Centre.
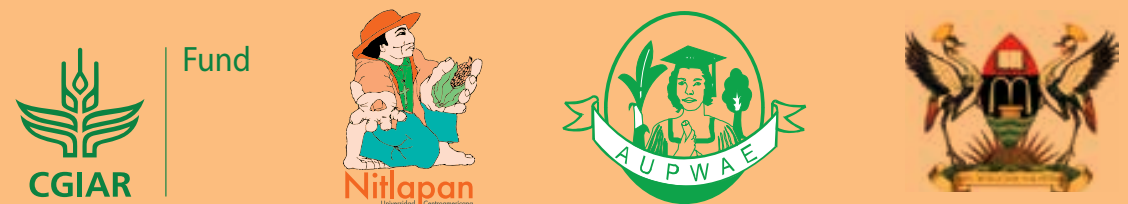

Austrian
Development Agency

\section{Center for International Forestry Research (CIFOR)}

CIFOR advances human well-being, environmental conservation and equity by conducting research to help shape policies and practices that affect forests in developing countries. CIFOR is a member of the CGIAR Consortium. Our headquarters are in Bogor, Indonesia, with offices in Asia, Africa and Latin America. 